\title{
COVID-19 and the Vasculature: Current Aspects and Long-Term Consequences
}

OPEN ACCESS

Edited by:

Jonatan Barrera-Chimal, Universidad Nacional Autónoma de México, Mexico

Reviewed by: ZhaoHui Tang,

Huazhong University of Science and

Technology, China Abdullah Shaito,

Qatar University, Qatar

*Correspondence:

Nadia Mercader

nadia.mercader@ana.unibe.ch

Britta Engelhardt

britta.engelhardt@tki.unibe.ch Robert Rieben

robert.rieben@dbmr.unibe.ch Yvonne Döring

yvonne.doering@insel.ch

${ }^{t}$ These authors have contributed equally to this work and share first authorship

Specialty section:

This article was submitted to Signaling,

a section of the journal Frontiers in Cell and Developmental Biology

Received: 29 November 2021 Accepted: 20 January 2022 Published: 15 February 2022

Citation:

Martínez-Salazar B, Holwerda M,

Stüdle C, Piragyte I, Mercader N, Engelhardt $B$, Rieben $R$ and Döring $Y$ (2022) COVID-19 and the Vasculature:

Current Aspects and LongTerm Consequences. Front. Cell Dev. Biol. 10:824851. doi: 10.3389/fcell.2022.824851
Berenice Martínez-Salazar ${ }^{1,2 \dagger}$, Melle Holwerda ${ }^{2 \dagger}$, Chiara Stüdle ${ }^{3 t}$, Indre Piragyte ${ }^{2,4 t}$, Nadia Mercader ${ }^{2,4,5,6 *}$, Britta Engelhardt ${ }^{3 *}$, Robert Rieben ${ }^{2 *}$ and Yvonne Döring ${ }^{1,2,7,8 *}$

${ }^{1}$ Division of Angiology, Swiss Cardiovascular Center, Inselspital, Bern University Hospital, University of Bern, Bern, Switzerland, ${ }^{2}$ Department for BioMedical Research (DBMR), University of Bern, Bern, Switzerland, ${ }^{3}$ Theodor Kocher Institute, University of Bern, Bern, Switzerland, ${ }^{4}$ Institute of Anatomy, University of Bern, Bern, Switzerland, ${ }^{5}$ Centro Nacional de Investigaciones Cardiovasculares (CNIC), Madrid, Spain, ${ }^{6}$ Bern Center of Precision Medicine BCPM, University of Bern, Bern, Switzerland, ${ }^{7}$ Institute for Cardiovascular Prevention (IPEK), Ludwig-Maximilians-University Munich (LMU), Munich, Germany, ${ }^{8}$ DZHK (German Centre for Cardiovascular Research), Partner Site Munich Heart Alliance, Munich, Germany

Severe Acute Respiratory Syndrome Coronavirus 2 (SARS-CoV-2) was first identified in December 2019 as a novel respiratory pathogen and is the causative agent of Corona Virus disease 2019 (COVID-19). Early on during this pandemic, it became apparent that SARS-CoV-2 was not only restricted to infecting the respiratory tract, but the virus was also found in other tissues, including the vasculature. Individuals with underlying preexisting co-morbidities like diabetes and hypertension have been more prone to develop severe illness and fatal outcomes during COVID-19. In addition, critical clinical observations made in COVID-19 patients include hypercoagulation, cardiomyopathy, heart arrythmia, and endothelial dysfunction, which are indicative for an involvement of the vasculature in COVID-19 pathology. Hence, this review summarizes the impact of SARS-CoV-2 infection on the vasculature and details how the virus promotes (chronic) vascular inflammation. We provide a general overview of SARS-CoV-2, its entry determinant Angiotensin-Converting Enzyme II (ACE2) and the detection of the SARSCoV-2 in extrapulmonary tissue. Further, we describe the relation between COVID-19 and cardiovascular diseases (CVD) and their impact on the heart and vasculature. Clinical findings on endothelial changes during COVID-19 are reviewed in detail and recent evidence from in vitro studies on the susceptibility of endothelial cells to SARS-CoV-2 infection is discussed. We conclude with current notions on the contribution of cardiovascular events to long term consequences of COVID-19, also known as "LongCOVID-syndrome". Altogether, our review provides a detailed overview of the current perspectives of COVID-19 and its influence on the vasculature.

Keywords: SARS-CoV-2, COVID-19, long COVID-19 syndrome, endothelium, heart

Abbreviations: + , positive; - , negative; IF, Immunofluorescence; IHC, Immunohistochemistry; ALT, Alanine transaminase; AST, Aspartate transaminase; GGT, Gamma-glutamyl transferase. 


\section{INTRODUCTION}

Severe acute respiratory syndrome coronavirus 2 (SARS-CoV-2) belongs to the Betacoronavirus family and was identified in December 2019/January 2020 in lung tissue of patients with symptoms resembling severe pneumonia, including acute respiratory distress syndrome (ARDS). This new disease was named Corona Virus disease 2019 (COVID-19) (Zhu N. et al., 2020). SARS-CoV-2 shares $79 \%$ similarity with SARS-CoV, another Coronavirus responsible for the SARS outbreak in 2002-2004 (Drosten et al., 2003; Kuiken et al., 2003; Lu et al., 2020). The single-stranded positive-sense viral RNA genome of SARS-CoV-2 encodes around 29 proteins from which 4 are structural proteins: spike (S), envelope (E), membraneassociated $(\mathrm{M})$, and nucleocapsid $(\mathrm{N})$ protein (Yao $\mathrm{H}$. et al., 2020). The $S$ protein is most important for the virus to enter the cell via its interaction with Angiotensin Converting Enzyme II (ACE2) and the transmembrane serine protease 2 (TMPRSS2) that cleaves the viral $\mathrm{S}$ protein facilitating its entrance into the cell (Hoffmann et al., 2020). Both $\mathrm{N}$ and $\mathrm{M}$ proteins are responsible for binding and packing the viral genome (Lu et al., 2021). The $\mathrm{N}$ protein further induces a strong immune response fostering the production of specific antibodies (IgA, IgG, and $\operatorname{IgM}$ ) which are also useful for diagnostic testing of COVID-19 (Zeng et al., 2020; Barlev-Gross et al., 2021; De Marco Verissimo et al., 2021).

Approximately half of the patients with COVID-19 are asymptomatic or mildly symptomatic, but 3-10\% of patients with COVID-19 require hospitalization, of which up to $20 \%$ may suffer from severe disease leading to a high mortality rate (Berlin et al., 2020). Patients with severe to critical illness display hypoxemia and dyspnea, which may develop into ARDS (Berlin et al., 2020). This stage of the disease is characterized by high circulating levels of pro-inflammatory cytokines, such as interleukin-6 (IL-6), IL-1 $\beta$, and IL-18 referred to as "cytokine storm" (Mehta et al., 2020), and the development of a prothrombotic state (Iba et al., 2020). Within the group of patients with severe COVID-19, there are significantly more individuals with pre-existing comorbidities of the cardiovascular system like elevated cholesterol levels, high blood pressure or a history of myocardial infarction (Figure 1). Endothelial dysfunction is generally present in infections caused by highly pathogenic Coronaviruses and has been shown to be particularly pronounced in SARS-CoV-2 infections resulting in damage of the pulmonary and other vascular endothelium (Teuwen et al., 2020). This suggests a synergistic activation of vascular inflammatory pathways that are associated with both severe COVID-19 and cardiometabolic diseases (Kadosh et al., 2020). In addition to alveolar damage in COVID-19 patients, vascular wall edema, hyaline thrombi, microhemorrhages, and diffuse thrombosis of peripheral small vessels contribute to disease severity (Carsana et al., 2020; Fox et al., 2020). One reason for vascular cell damage may be the high concentration of circulating proinflammatory cytokines and ferritin in severe COVID-19 patients (Carubbi et al., 2021; Gao et al., 2021). The latter is also reflected by high concentrations of circulating soluble P-selectin in COVID-19 patients who were admitted to intensive care units (ICU) compared to patients who did not require intensive care (Goshua et al., 2020). In addition, elevated levels of thrombomodulin (a membrane-bound regulator of coagulation, which is released during endothelial cell injury) were also associated with an increased risk of mortality in COVID-19 patients (Goshua et al., 2020). Similarly, increase of circulating endothelial cells in patients with COVID-19 correlated with a higher number of platelets and lymphocytes and the inflammatory endothelial marker soluble vascular cell adhesion molecule 1 (sVCAM1) (Guervilly et al., 2020).

Taken together, severe COVID-19 may present as a hyperinflammatory prothrombotic disease with multiorgan involvement affecting the entire vasculature. The presence of pre-existing cardiovascular disease (CVD) is associated with an increased risk for a more severe disease course and higher mortality. Moreover, long-term consequences of SARS-CoV-2 infection, now referred to as "Long COVID-19 syndrome (LCS)" (Venkatesan, 2021), negatively impact the heart and the vascular system, however, these effects are poorly understood (Figure 2). Hence, in this review, we will focus on the impact of SARS-CoV-2

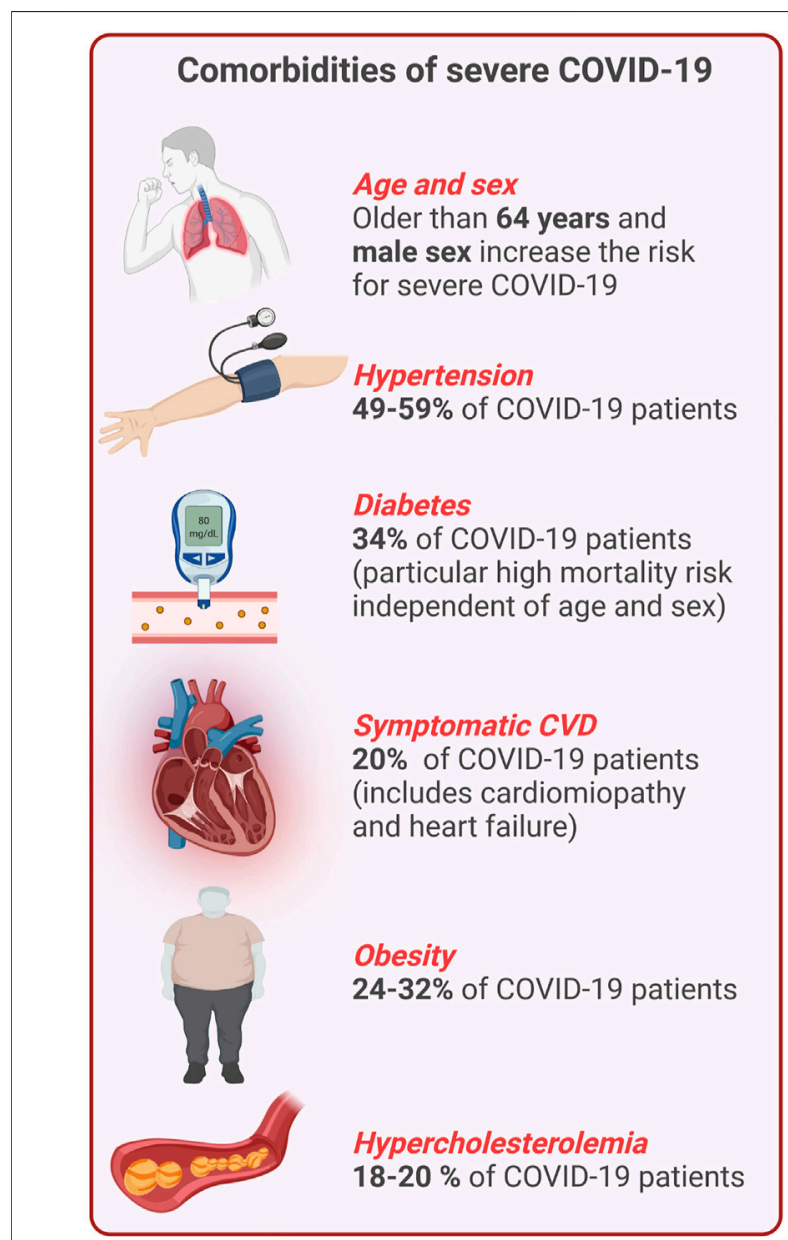

FIGURE 1 | Overview of comorbidities of severe COVID-19 and CVD. Percentages indicate the frequency of certain comorbidities and COVID-19 (This figure was made with biorender.com). 


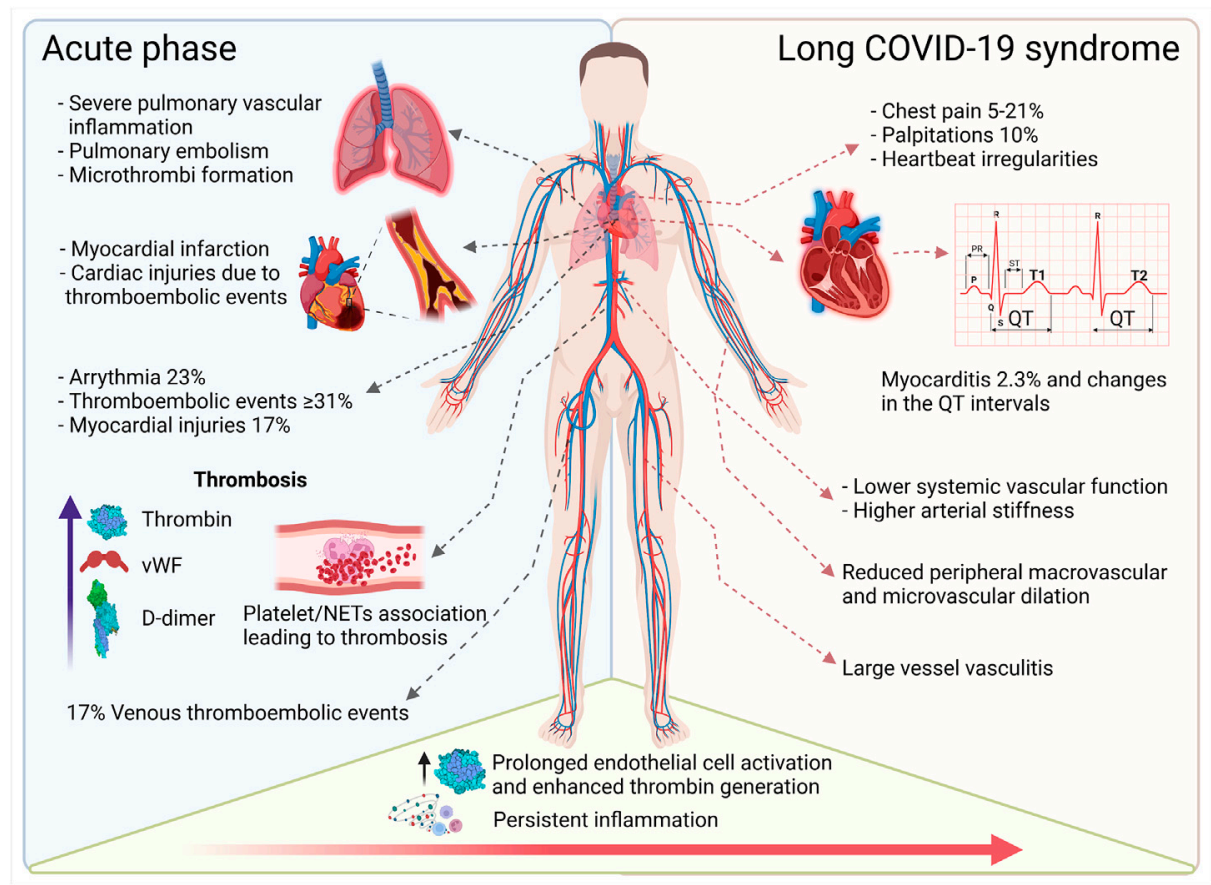

FIGURE 2 | Overview of cardiovascular complications in acute and long-term COVID-19. The acute phase of COVID-19 induces pulmonary, cardiac, and peripheral thrombotic events and can trigger arrythmia and myocardial injury. Persistent inflammation and accompanying vascular dysfunction foster cardiac complications such as palpitations and myocarditis. Ongoing (chronic) vascular inflammation increases vascular stiffness and reduces micro- and macrovascular dilatation (This figure was made with biorender.com).

infection on the vascular system and detail how this pathogen promotes chronic inflammation and vascular damage, which may contribute to the development of LCS.

We will first discuss SARS-CoV-2 and its entry route, followed by a summary of what has been described about COVID-19 and CVD. Thereafter, the impact of SARS-CoV-2 on vascular cells will be debated based on what has been reported in vivo and in vitro (Figure 3 ). Finally, LCS and its potential impact on cardiovascular health will be summarized.

\section{SARS-COV-2}

\subsection{Viral Replication, S (Spike) Protein and Angiotensin-Converting Enzyme 2 (ACE2)}

The replication cycle of SARS-CoV-2 is initiated when the S protein binds the entry receptor ACE2 and is subsequently cleaved by a host protease such as TMPRSS2 at the plasma membrane, or endosomal cathepsins, allowing for either direct fusion with the plasma membrane or the endosome (Hoffmann et al., 2020; V'kovski et al., 2021b). Inside the infected cell structural proteins of the virus such as the $\mathrm{S}$ and $\mathrm{N}$ protein, are generated and, together with the newly formed genomic RNA, assembled (V'kovski et al., 2021b) and released from the infected cell via exocytosis. These newly formed virus particles are ready to infect new cells in the next round of viral infection.

The S protein is a type I transmembrane glycoprotein sharing around $73 \%$ sequence identity with SARS-CoV (Lu et al., 2020).
Further, it is a trimer composed of subunit 1 (S1), which contains the receptor binding domain (RBD), and the subunit 2, which is linked to $\mathrm{S} 1$ through a junction region that is susceptible to cleavage by furin. Cleavage of S2 by TMPRSS2 leads to the exposure of the fusion peptide allowing for fusion of the viral-host membranes facilitating the entrance of the virus into the cell (Hoffmann et al., 2020; Jaimes et al., 2020; Walls et al., 2020; Papa et al., 2021).

Thus, $S$ protein initiates the entrance of the virus to the host cell through direct binding of the RBD with the peptidase domain of ACE2, which is described as the main entry receptor for SARSCoV-2 (Hoffmann et al., 2020; Yan et al., 2020).

Despite RNA viruses being prone for mutations or adaptations in their viral genome, the evolutionary changes of SARS-CoV-2 have been limited until now (Korber et al., 2020). Most adaptations have been observed in the $S$ protein, with the first report being the single amino acid change D614G (Glycine $(\mathrm{G})$ substitutes Aspartic acid (D) in the amino acid position 614), becoming the first predominant strain circulating in Europe. Compared with the original strain isolated from patients in Wuhan, D614G was able to enhance the spread of the virus including an increased infectivity which resulted in higher viral titers in infected patients and more severe disease outcome (Korber et al., 2020; Onder et al., 2020).

The variants alpha, beta, gamma, delta, and omicron have important mutations in the $S$ protein leading to an increased transmission and/or hospitalization rate, respectively (Li M. et al., 2021; Cameroni et al., 2021; Kumar et al., 2021). Most variations occurred in the RBD resulting in a higher affinity for the receptor 


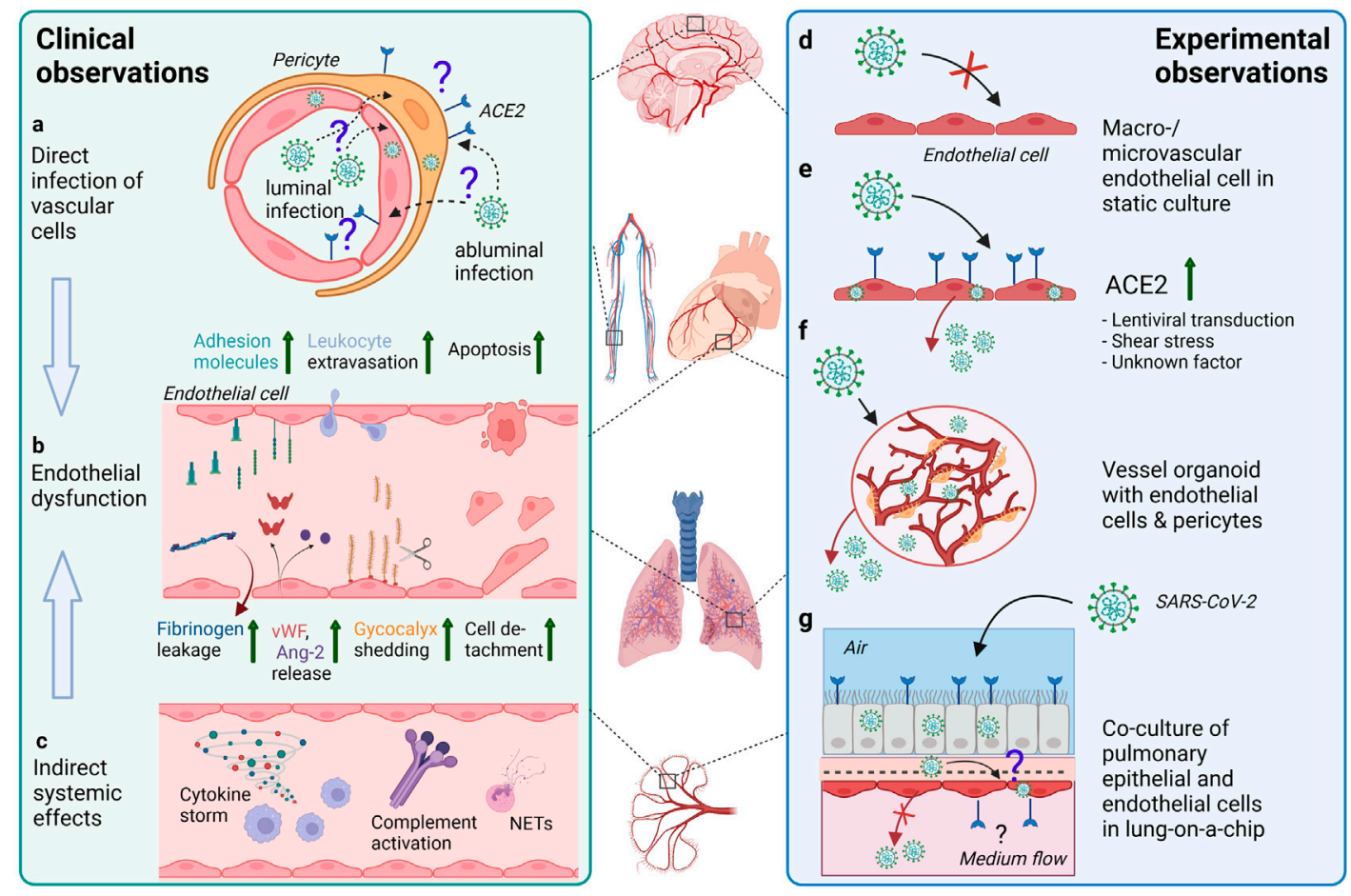

FIGURE 3 | Effects of SARS-CoV-2 infection on the endothelium as observed in patients and different experimental models. (A) In endothelial cells in various organs (such as depicted in the middle of the figure) from COVID-19 patients, SARS-CoV-2 RNA or protein has been inconsistently detected. The ACE2 expression is rather found in pericytes than endothelial cells. Infection of vascular cells can happen from the abluminal side at primary sites of infection in the respiratory tract or from the luminal side in case of hematogenous SARS-CoV-2 dissemination to distal organs. To what extent infection of endothelial cells and/or pericytes occurs and contributes to COVID-19 pathology is unclear. (B) Endothelial dysfunction is not only observed in the pulmonary vasculature, but throughout the body as a hallmark of severe COVID-19 and may be one of the main contributors to increased frequency of thrombotic events. Elevated levels of markers of endothelial activation and injury including von Willebrand factor (VWF), angiopoietin-2 (Ang-2), soluble forms of several cell adhesion molecules and glycocalyx degradation products, and increased numbers of detached endothelial cells are found in COVID-19 patients' blood. Postmortem analysis of multiple organs has revealed perivascular immune cell infiltrates, decreased endothelial barrier properties as visualized by fibrinogen leakage and endothelial apoptosis in some of the COVID-19 patients. (C) Besides direct infection of vascular cells, immune-mediated mechanisms such as excessive pro-inflammatory cytokine production or complement-hyperactivation can play a major role in causing endothelial dysfunction. (D) Macro- and microvascular endothelial cells isolated from different anatomical locations (such as depicted in the middle of the figure) in conventional monolayer culture were not permissive to infection by SARS-CoV-2. (E) When ACE2 was introduced into endothelial cells by lentiviral transduction productive infection occurred. ACE2 expression in endothelial cells might also be induced by shear stress or certain interferons. (F) In co-culture models such as hiPSCderived vessel organoids consisting of endothelial cells and pericytes, productive infection occurred, (G) whereas in lung-on-a-chip-models infection of the lung epithelial compartment can lead to infection and cytopathogenic effects of the adjacent endothelial cells (This figure was made with biorender.com).

ACE2 and in supporting escape from antibody neutralization, this includes for example variants B.1.1.7, B.1.526 and B.1.429 of the alpha lineage (Wang P. et al., 2021; Liu et al., 2021; West et al., 2021). The beta variant B.1.351 was the one responsible for the high transmission rate in South Africa with the highest frequency of mutations located in the S protein, namely $77 \%$ (Wang P. et al., 2021). The delta variant B.1.617.2 first described during the second wave of COVID-19 in India, gained particular attention as it demonstrated an increased infectivity allowing a faster virus spreading and enhanced immune evasion due to a reduced susceptibility to antibodies elicited by earlier SARS-CoV-2 variants or the respectively designed vaccines (Augusto et al., 2021; Planas et al., 2021). Omicron (B.1.1.529), now taking over, was first detected in November 2021 and is substantially mutated compared to any previously described SARS-CoV-2 variant, including $37 \mathrm{~S}$ protein residue substitutions in the predominant haplotype. This high mutation rate suggests that omicron might escape infectionand vaccine-elicited antibody treatment (Hoffmann M. et al., 2021; Cameroni et al., 2021). Altogether, multiple studies have demonstrated the importance of the $S$ protein in the infectivity and pathogenicity of the SARS-CoV-2. Mutations of the S protein are a key factor determining stability/strength of the $S$ protein and ACE2 interaction thus consequently also spreading and immune evasion.

ACE2, the most important entry receptor of SARS-CoV-2, is a homologue of ACE and is a key anti-inflammatory component of the Renin Aldosterone Angiotensin System (RAAS), an important regulator of blood pressure as well as renal, vascular and myocardial function and physiology (Donoghue et al., 2000; Crackower et al., 2002; Paul et al., 2006; Santos et al., 2018; Beyerstedt et al., 2021; Kuriakose et al., 2021) ACE2 is an antiinflammatory regulator by converting Ang II into Ang (1-7) and 
Ang (1-9) (Donoghue et al., 2000; Kuriakose et al., 2021). ACE2 exists in two forms, a transmembrane (tACE2) and a soluble (sACE2) form. The ACE2 ectodomain contains a proteolytic cleavage site for ADAM-17, a disintegrin and metalloprotease that releases sACE2 into the circulation (Kuriakose et al., 2021). sACE2 preserves the $\mathrm{N}$-terminal peptidase domain and is therefore able to interact with the $\mathrm{S}$ protein of SARS-CoV-2, resulting in the formation of a complex that can enter the cell through endocytosis via the Angiotensin-II-receptor type 1 (Yeung et al., 2021). This mechanism has also been addressed in a therapeutic manner by increasing the concentration of recombinant sACE2 (rsACE2) in the human circulation to prevent infection. Both sACE2 and rsACE2 scavenge SARS$\mathrm{CoV}-2$, reducing infectivity in cell culture assays (Cocozza et al., 2020; Glasgow et al., 2020) and in a human vascular organoid model in vitro (Monteil et al., 2020). Nevertheless, at the beginning of the COVID-19 pandemic, ACE2 inhibitors or angiotensin receptor blockers, already used for treatment of hypertension, were discussed to have negative effects in COVID-19 patients (Fang et al., 2020; Hammoud et al., 2021), as the treatment leads to an increase in ACE2 expression levels (Hoffmann et al., 2020). Yet, recent clinical data indicate that COVID-19 patients with ongoing hypertension therapy have improved clinical outcomes (Yang G. et al., 2020; Bean et al., 2020; Meng et al., 2020; Safizadeh et al., 2021).

ACE2 is highly expressed together with the TMPRSS2 protease in type II pneumocytes in the lung, in absorptive enterocytes in the intestine, and secretory goblet cells in the nasal epithelium (Lukassen et al., 2020; Ziegler et al., 2020). Both molecules were also shown to be present in heart, cornea, and kidney. These observations might explain why COVID-19 is a systemic disease with multiple tissues involved in the progression and clinical outcome (Hikmet et al., 2020; Sungak et al.,2020).

\subsection{Virus Detection in Pulmonary and Extrapulmonary Tissue}

SARS-CoV-2 is a respiratory pathogen that mainly transmits via aerosols and targets epithelial cells located in the respiratory tract, which represent the main entry port and primary replication site inside the human body (Jonsdottir and Dijkman, 2016). The respiratory tract can be divided into two distinct compartments, namely the upper (from the nasal cavity to the larynx) and lower (from the trachea to the bronchi) respiratory tract, known for their different ambient temperatures of approximately 33 and $37{ }^{\circ} \mathrm{C}$, respectively (Mcfadden et al., 1985). Both compartments are lined with multiple types of epithelial cells including ciliated, mucus-secreting goblet, columnar and basal cells in a pseudostratified manner (Zepp and Morrisey, 2019). The cellular tropism of the SARS-CoV-2 is described to be ciliated (Hou et al., 2020; Ahn et al., 2021; Ravindra et al., 2021; Robinot et al., 2021) or non-ciliated cells (V'kovski et al., 2021a). Infection with SARS-CoV-2 leads to transcriptional alterations in ciliated and non-ciliated cells, which eventually cause activation of the innate immune response and subsequent cytokine release (Chen et al., 2021). In addition, the different temperatures of the upper and lower respiratory tract can have a distinct effect on the replication kinetics. In vitro, SARS-CoV-2 infection leads to \pm 10 fold higher viral titers in well-differentiated airway epithelial cells incubated at $33^{\circ} \mathrm{C}$ compared to $37^{\circ} \mathrm{C}$ (V'kovski et al., 2021a). In vivo, the higher viral loads might also be linked to an altered innate immune response or to varying cellular host factors that facilitate viral infection (Hoffmann H.-H. et al., 2021; Yan et al., 2021). However, despite its preference for the respiratory tract, SARS-CoV-2 is also observed in other tissues of COVID-19 patients. Similarly, the blood vessels supplying these organs are also prone to damage by SARS-CoV-2-mediated inflammation. Therefore, the following paragraphs will provide a short overview of important organs which may also be targeted by SARS-CoV-2.

Gastrointestinal Tract: Viral transcripts could be observed in stool and rectal swabs during later stages of viral infection, suggesting that the oral route is another pathway for viral entry (Parasa et al., 2020; Xiao et al., 2020). Indeed, staining for SARS-CoV-2 N protein in different anatomical regions of the gastrointestinal tract of COVID-19 patients revealed positive signals in the glandular epithelium of the stomach, duodenum, and rectum, but not in the esophagus, which correlated with ACE2 expression of the respective tissue (Xiao et al., 2020).

Liver: Immunohistology analysis of liver biopsies taken from COVID-19 patients post-mortem showed that viral RNA can be visualized using in situ hybridization in blood clots and in the endothelium of the liver (Sonzogni et al., 2020). Hepatocytes might be susceptible to direct viral infection since syncytium formation and apoptotic cells have been observed in COVID-19 patients, which could also explain the hepatic impairment (Wang Y. et al., 2020).

Central Nervous System (CNS): A broad range of neurological symptoms observed in patients with mild to severe disease such as ageusia, anosmia, headache, fatigue, deficits in cognitive and memory function, delirium or altered mood suggests that SARS-CoV-2 also affects the CNS (Ellul et al., 2020; Pajo et al., 2021; Rogers et al., 2021). Viral RNA and/or protein in various brain regions post-mortem has been infrequently and inconsistently detected (Meinhardt et al., 2021; Pajo et al., 2021; Song et al., 2021) and viral RNA has been rarely detected in cerebrospinal fluid of SARS-CoV-2 infected patients (Lewis et al., 2021). Inoculation of human pluripotent stem cell (hPSC)derived brain organoids with SARS-CoV-2 revealed absent or mostly abortive infection of neurons and/or astrocytes, pointing towards the notion of limited neurotropism and replication in the CNS of SARS-CoV-2 (Ramani et al., 2021). The frequent loss of smell and the high viral load in the olfactory epithelium of COVID-19 patients (Meinhardt et al., 2021) brought the CNS entry route via axons of the olfactory receptor cells into focus, but this has not been confirmed (Khan et al., 2021).

Other potential targets of SARS-COV-2 in the CNS are the choroid plexus epithelial cells (Jacob et al., 2020; Pellegrini et al., 2020; Yang A. C. et al., 2021; Fuchs et al., 2021) brain microvascular endothelial cells (Bhatnagar et al., 2021; Meinhardt et al., 2021; Nuovo et al., 2021; Schwabenland et al., 2021; Song et al., 2021) and pericytes (Bocci et al., 2021).

Pancreas: In post-mortem material of COVID-19 patients, the viral $\mathrm{N}$ protein was detected in $\beta$-cells located in islets of the 
pancreas, which have been proposed as potential site of viral replication (Müller et al., 2021; Qadir et al., 2021). This resulted in an impaired production of insulin upon stimulation with glucose in vitro and could be the reason for the hyperglycemia observed in COVID-19 patients (Zhu L. et al., 2020; Affinati et al., 2021; Montefusco et al., 2021; Müller et al., 2021).

Kidney: Acute kidney injury has been observed in COVID-19 patients including collapsing glomerulopathy, heavy proteinuria and podocytopathy (Braun et al., 2020; Cheng et al., 2020; Shetty et al., 2021). Viral transcripts have been detected in all compartments of the kidney with the highest levels found in the glomeruli (Puelles et al., 2020).

To conclude, infection of SARS-CoV-2 is not limited to the respiratory tract. An overview of the different sites of viral infection is provided in the Table 1. Putative direct infections of heart and vasculature will be detailed in Section 3 and Section 4.

\section{COVID-19 and Cardiovascular Disease (CVD)}

CVD is a class of diseases affecting the heart and blood vessels. CVD includes for example coronary and cerebral artery diseases as well as peripheral artery disease, thromboembolic disease, and venous thrombosis. The most abundant pathophysiology underlying CVD is atherosclerosis, describing a disease of the arterial intima caused by modified lipids and infiltrating inflammatory immune cells mediating endothelial dysfunction. The inflamed intima grows and forms a plaque, which may progress and calcify. Luminal extension of the intimal lesion may lead to vasoconstriction or occlusion while unstable plaques may rupture and cause arterial thrombosis (Soehnlein and Libby, 2021). Causal mechanisms vary but the underlying risk factors for CVD are high blood pressure, smoking, diabetes mellitus, lack of exercise, obesity, and high blood cholesterol - among others. Moreover, age and sex co-determine the individual CVD risk (Stark and Massberg, 2021).

\subsection{Clinical Observations}

CVD manifestations in COVID-19 patients are observed regularly in hospitalized cases. Several types of complications have been identified and their etiology is truly diverse (Chung et al., 2021). Combination of CVD and SARS-CoV-2 infection closely correlates with the severity of COVID-19 progression and mortality (Chung et al., 2021) (Figure 1). These observations were also made with SARS-CoV, which showed similar tendencies (Booth et al., 2003; Chan et al., 2003). Retrospective analysis of COVID-19 patients revealed CVD in $8 \%$ to approximately $62 \%$ of all hospitalized cases (Zhou P. et al., 2020; Giustino et al., 2020; Sandoval et al., 2020). About one third of all COVID-19 related deaths had underlying CVD (Guo et al., 2020; Onder et al., 2020). The latter suggests a synergistic activation of cardiovascular inflammatory pathways that are associated with both COVID-19 and cardiometabolic disorders (Kadosh et al., 2020). For example, cells of the cardiovascular system, in addition to the respiratory tract, may also represent a direct target for infection with SARS-CoV-2 due to the expression of ACE2 (Groß et al., 2020). ACE2 is also known to be overexpressed in diabetic patients which may facilitate COVID-19 in this population (Cummings et al., 2020; Richardson et al., 2020). Out of 5,700 COVID-19 patients in a cohort from New York, 34\% had pre-existing diabetes (Cummings et al., 2020). Further, hypertension and obesity are frequent among Northern Americans (Chobufo et al., 2020), and both comorbidities correlated with a higher mortality of COVID19 patients (Woolf et al., 2020). Early on in China, the case fatality rate for people with hypertension was about 6 and 10.5\% for people with pre-existing CVD (Wu and Mcgoogan, 2020). In a global meta-analysis of 45 studies with a total of 18,300 patients, diabetes was identified as the second common comorbidity after hypertension, and those patients were prompted to a higher risk of in-hospital death independently of age and sex (Silverio et al., 2021). Also Italy reported that patients with comorbidities such as hypertension, hypercholesterolemia, diabetes, and heart disease have an increased risk of mortality (Grasselli et al., 2020; Huang et al., 2020).

\subsection{Specific Factors of COVID-19 and CVD}

Coagulopathies: Coagulopathies have also been associated with SARS-CoV-2 infection, independently of pre-existing CVD. In fact, D-dimer levels (a fibrin degradation product used to determine the activation of the coagulation cascade), are enhanced in acute COVID-19 cases (Zhou F. et al., 2020; Berger et al., 2020). Different reports have found a correlation between the increase of D-dimer levels and COVID-19 severity with an about 7 -fold increase in critically ill patients, associated with an increased mortality risk (Zhou F. et al., 2020; Yao Y. et al., 2020). In addition, neutrophils and monocytes are strongly contributing to the development of ARDS and thrombosis by inducing hyperinflammation. Neutrophil Extracellular Traps (NETs) are extracellular decondensed chromatin structures mixed with antimicrobial proteins and released in response to infections. Biomarkers of NET formation were increased in the circulation of patients with severe COVID-19 and related to thrombotic events as for example high levels of neutrophilplatelet aggregations were detected (Middleton et al., 2020; Nicolai et al., 2020; Dennison et al., 2021).

Atherosclerosis: Ill-alliance of atherosclerotic endothelial dysfunction and SARS-CoV-2-triggered acute inflammatory responses may accelerate atherosclerotic lesion growth and plaque rupture. This notion is supported by reports from cases of acute myocardial infarction with spontaneous dissection of coronary arteries in patients affected by severe manifestations of COVID-19 (Courand et al., 2020; Long et al., 2020; Romiti et al., 2020). Moreover, statin treatment, which is the gold standard therapy to lower cholesterol levels in CVD patients to limit hyperlipidemia, was shown to reduce in-hospital mortality in patients with diabetes mellitus and COVID-19 (Saeed et al., 2020) and its use was also independently associated with lower intensive care unit admission (Tan et al., 2020). Most likely benefits of statin treatment in this context are rather due to its antiinflammatory and not to its lipid-lowering function. In addition, it seems that lesion composition does impact on the risk for CVD-associated complications in COVID-19 since 
TABLE 1 | Overview of various organs susceptible to viral infection with SARS-CoV-2 and their clinical symptoms in COVID-19 patients.

\begin{tabular}{|c|c|c|c|c|c|}
\hline Organ/tract & Cellular tropism & $\begin{array}{c}\text { Viral } \\
\text { transcripts } \\
\text { detected }\end{array}$ & $\begin{array}{l}\text { Viral immune- } \\
\text { staining } \\
\text { in material } \\
\text { of COVID-19 } \\
\text { patients (IF } \\
\text { or IHC) }\end{array}$ & $\begin{array}{c}\text { Clinical symptoms } \\
\text { in COVID-19 } \\
\text { patients }\end{array}$ & References \\
\hline Respiratory tract & (Non-) ciliated cells & + & + & Acute respiratory distress syndrome (ARDS) & $\begin{array}{l}\text { (Hou et al., } 2020 \\
\text { Ahn et al., 2021; } \\
\text { Ravindra et al., } 2021 \\
\text { Robinot et al., } 2021 \\
\text { V'kovski et al. 2021a) }\end{array}$ \\
\hline $\begin{array}{l}\text { Gastrointestinal } \\
\text { tract }\end{array}$ & $\begin{array}{l}\text { Glandular epithelium, } \\
\text { enterocytes }\end{array}$ & + & + & Diarrhea, nausea, and vomiting & $\begin{array}{l}\text { (Parasa et al., } 2020 \\
\text { Xiao et al., 2020) }\end{array}$ \\
\hline Liver & $\begin{array}{l}\text { Hepatocytes, } \\
\text { Cholangiocytes }\end{array}$ & + & + & $\begin{array}{l}\text { Elevated levels of metabolic enzymes (ALT, AST, GGT), } \\
\text { steatosis, fibrosis and cirrhosis, thrombosis }\end{array}$ & $\begin{array}{l}\text { (Lagana et al., } 2020 \\
\text { Sonzogni et al., } 2020 \\
\text { Lopez-Mendez et al., } \\
\text { 2021) }\end{array}$ \\
\hline Heart & Cardiomyocytes & + & + & Heart injury, arrythmias, myocarditis & $\begin{array}{l}\text { (Huang et al., } 2020 \\
\text { Rey et al., } 2020 \\
\text { Coromilas et al., } 2021 \\
\text { Pellegrini et al., 2021) }\end{array}$ \\
\hline Pancreas & $\beta$-cells & + & + & Pancreatitis, onset type 1 Diabetes Mellitus, ketoacidosis & $\begin{array}{l}\text { (Akarsu et al., } 2020 \\
\text { Hadi et al., } 2020 \\
\text { Wang et al., } 2020 \text { a } \\
\text { Pandanaboyana et al., } \\
\text { 2021) }\end{array}$ \\
\hline Kidney & $\begin{array}{l}\text { Proximal tubular } \\
\text { epithelium, glomeruli }\end{array}$ & + & + & Glomerulopathy, heavy proteinuria and podocytopathy & $\begin{array}{l}\text { (Braun et al., } 2020 \\
\text { Cheng et al., } 2020 \\
\text { Puelles et al., } 2020 \\
\text { Shetty et al., 2021) }\end{array}$ \\
\hline $\begin{array}{l}\text { Reproductive } \\
\text { system }\end{array}$ & Not determined & $?$ & $?$ & Hypospermatogenesis & $\begin{array}{l}\text { (Yang et al., 2020b } \\
\text { Ma et al., 2021b) }\end{array}$ \\
\hline $\begin{array}{l}\text { Central nervous } \\
\text { system }\end{array}$ & Not clear & $+/-$ & $+/-$ & Cognitive deficits, headaches & $\begin{array}{l}\text { (Meinhardt et al., } 2021 \\
\text { Pajo et al., } 2021 \\
\text { Song et al., 2021) }\end{array}$ \\
\hline Vasculature & $\begin{array}{l}\text { Endothelial cells; } \\
\text { pericytes }\end{array}$ & - & + & Endothelial dysfunction & $\begin{array}{l}\text { (He et al., } 2020 \\
\text { Teuwen et al., } 2020 \\
\text { Varga et al., } 2020 \\
\text { Maccio et al., 2021) }\end{array}$ \\
\hline
\end{tabular}

higher calcification was correlated with a higher risk of severe COVID-19 (Dillinger et al., 2020). To shed more light on the impact of atherosclerosis for COVID-19 Das and Podder retrieved data of differentially expressed genes for both, atherosclerosis, and COVID-19, from publicly available microarray and RNAseq datasets and performed a proteinprotein interaction network analysis. Further functional enrichment revealed inflammatory response genes to be more abundant, particularly MyD88 was identified as a crucial linker of atherosclerosis and COVID-19 (Das and Podder, 2021).

Non-modifiable risk factors: Moreover, and similar to CVD, age and sex are risk factors for severe COVID-19 (FernandezMartinez et al., 2021; Wehbe et al., 2021). Italy, hit hardly by the first wave in early 2020, reported that patients older than 64 years had an increased mortality risk compared to younger individuals
(Grasselli et al., 2020) and people with more than 70 years of age even displayed a case fatality rate of $22.7 \%$ (Onder et al., 2020). In addition, available data points towards an increased risk of mortality for male patients with COVID-19 worldwide (PerezLopez et al., 2020). An overview of shared comorbidities of CVD and COVID-19 is provided in Figure 1.

\subsection{COVID-19 and the Heart}

According to literature, human cardiomyocytes express only relatively low amounts of ACE2 compared to other heart residing cells such as pericytes or fibroblasts (Chen et al., 2020; Hikmet et al., 2020; Litviňuková et al., 2020; Nicin et al., 2020). Yet, individuals with dilated cardiomyopathy have almost two-fold higher expression of ACE2 in the left ventricle (Bristow et al., 2020). Cardiomyocytes may be directly infected by SARS- 
CoV-2 or harmed in an indirect manner through the inflammatory response induced by the virus (Yang L. et al., 2021). Human induced pluripotent stem cell-derived cardiomyocytes (hiPSC-CMs) were shown to be susceptible to viral infection (Bojkova et al., 2020; Sharma et al., 2020; Wong et al., 2020; Yang L. et al., 2021; Marchiano et al., 2021) and mimicked cytopathic features of COVID-19 patients' hearts (Bermejo-Martin et al., 2020; Marchiano et al., 2021). A recent study using an in vivo hamster model for SARS-CoV-2 infection showed direct infection of mature cardiomyocytes and revealed that the same mechanism of monocyte recruitment via the chemokine CCL2 occurs in vivo, as observed in hiPSC-CMs or in samples from mature cardiomyocytes (Yang L. et al., 2021). Furthermore, active viral replication was reported in infected hiPSC-CMs with a significant increase in the mRNA expression of inflammatory cytokines like IL-6, TNF- $\alpha$ and IL-8 (Wong et al., 2020). Similarly, these cytokines are elevated in COVID-19 patients with co-morbidities such as chronic kidney disease, diabetes, and hypertension (Del Valle et al., 2020). Elevated levels of TNF- $\alpha$ were also measured in patients with congestive heart failure and were shown to contribute to organ damage (Del Valle et al., 2020). SARS-CoV-2 infection also affected the electrical and mechanical function of hiPSC-CMs in the form of a reduced contractile function, lower depolarization of the spike amplitude and lower electrical conduction velocity due to the absence of the $\mathrm{Ca} 2+$ flux into the cells (Yang L. et al., 2021; Marchiano et al., 2021).

Initially it was thought that vascular complications in COVID19 patients, such as small vessel endothelitis and endothelial dysfunction in the heart (Maccio et al., 2021), were caused by direct viral infection of the endothelial cells (discussed in more depth in Section 4). Nevertheless, accumulating evidence now suggests that damage of the vascular system is rather mediated by an augmented inflammatory response (Garnier-Crussard et al., 2020). Indeed, up to $31 \%$ of COVID-19 patients in ICU units showed thromboembolic events (Klok et al., 2020), which contributes to the rate of cardiac injuries in the most severely ill COVID-19 patients (Roberts et al., 2020). Other acute cardiac symptoms associated with COVID-19 diagnosis were arrythmias, myocardial injury, and acute heart failure (Rey et al., 2020). Arrythmia was one of the main cardiac symptoms, with $23 \%$ of patients who presented with atrial fibrillation $(81,8 \%)$, followed by bradyarrhythmia $(22,6 \%)$, and ventricular arrythmia $(20,7 \%)$ (Rey et al., 2020; Coromilas et al., 2021). Myocardial injuries were reported in $17 \%$ of the hospitalized COVID-19 patients and echocardiograms of this group also revealed pericardial effusion and right ventricular myopericarditis (Rauch S. et al., 2020). Echocardiographic analysis elucidated that $13 \%$ of patients without a pre-existing CVD condition developed severe cardiac disease, and out of this group 3\% progressed to myocardial infarction or myocarditis (Dweck et al., 2020).

Another group of patients prone to get severe COVID-19 are patients with congenital heart disease (CHD) (Lewis et al., 2020; Zareef et al., 2020; Haiduc et al., 2021; Strah et al., 2021). CHD represents one of the most common developmental defects, affecting nearly 1 in 100 newborns and 90\% of these patients present with isolated cardiac defects. Notably, although complicated COVID-19 courses are more common in CHD patients, the mortality risk seems not to be significantly affected in adults with CHD and COVID-19 (Strah et al., 2021). In pediatric patients, Down syndrome with common atrioventricular canal is the most described CHD correlating with more severe COVID-19. However, mortality appears to be only increased in patients with aortic stenosis and complex CHD-like hypoplastic left heart syndrome (Strah et al., 2021). In general, larger cohort studies and more in-depth careful evaluations are required to better define subgroups within CHD patients carrying a higher risk of COVID19 associated mortality.

In conclusion, CVD and COVID-19 form an ill-alliance promoting severe cases (Figure 2). In particular, hypertension and diabetes in the elderly and pre-existing CHD increase the risk for severe disease courses with cardiac involvement. Nevertheless, while hyperinflammation certainly fosters cardiac disease in COVID-19, further studies still need to clarify to which extent mature human cardiomyocyte are susceptible to direct infection with SARS-CoV-2 or whether the observed cardiac effects are mostly due to damage caused by an augmented general inflammatory response.

\section{COVID-19 AND VASCULAR CELLS}

\subsection{General Aspects of Vascular Biology}

Endothelial cells line the inner wall of arteries, capillaries, and veins. Although endothelial cells share common properties, they exhibit large phenotypic variability to fulfill their organotypic functions. Their phenotypic heterogeneity arises not only from their position along the vascular tree, but more prominently from their tissue of origin (Aird, 2012; Kalucka et al., 2020; Paik et al., 2020). The endothelium functions as a selective and adaptive barrier to control the exchange of nutrients, metabolites, proteins and cells between the blood and the neighboring tissue. Endothelial cells govern vascular tone and flow through constant production of vasodilating nitric oxide (Humphrey and Schwartz, 2021), and maintain blood fluidity through production of a plethora of anticoagulant and antithrombotic factors (Neubauer and Zieger, 2021). The luminal side of all endothelial cells is covered by the glycocalyx, a non-uniform and complex layer composed of proteoglycans and glycoproteins, that is critically involved in regulation of all endothelial functions (Villalba et al., 2021). On the abluminal side of endothelial cells, perivascular fibroblasts, macrophages, adventitial and mural cells contribute to organotypic functional and structural integrity of vessels (Holm et al., 2018). While large arteries are surrounded by several layers of vascular smooth muscle cells (VSMCs) and perivascular adipose tissue, smaller vessels possess less layers. Venules and veins are incompletely covered with VSMCs, and capillaries and post-capillary venules contain pericytes as the only mural cell type, which are embedded in the same extracellular matrix as the endothelial cells (Van Dijk et al., 2015; Holm et al., 2018). Inadequate control of any of the above-mentioned endothelial cell functions is regarded as endothelial dysfunction and is proposed to be a major contributor to COVID-19 pathology including hypercoagulation (Teuwen et al., 2020; Maruhashi and Higashi, 2021; Nicosia et al., 2021). 


\subsection{Vascular Pathologies During COVID19 4.2.1 Increased Thrombotic Events}

COVID-19 is accompanied by a higher incidence rate of venous and arterial thrombotic events compared to historical influenza virus cohorts (Helms et al., 2020; Poissy et al., 2020; BurkhardKoren et al., 2021). Meta studies comprising several thousands of hospitalized COVID-19 patients estimated average incidence rates of $17 \%$ for venous thromboembolic events (VTE) (of which $12 \%$ were deep vein thrombosis (DVT) and $7.1 \%$ pulmonary embolism (PE)) or $18 \%$ for VTE (of which $14 \%$ were DVT and 8\% PE), respectively (Gratz et al., 2021; Jiménez et al., 2021). In line with the high incidence of thrombotic events, elevated D-dimer levels were found in hospitalized COVID-19 patients (Berger et al., 2020), which often correlated with COVID-19 severity (Tang et al., 2020; Thwaites et al., 2021). D-Dimer levels in COVID-19 patients exceeded the ones found in patients infected with influenza virus (Mei et al., 2020). Another commonly reported parameter that infers the procoagulant state of COVID-19 patients is the imbalance of von Willebrand factor (vWF) and ADAMTS13 (cleaves ultra-large vWF multimers), as evidenced by increased vWF antigen levels and decreased ADAMTS13 activity in hospitalized COVID-19 patients' plasma (Favaloro et al., 2021). Notably, the increased vWF to ADAMTS13 ratio was accentuated in COVID-19 patients with a fatal outcome (Bazzan et al., 2020; Delrue et al., 2021; Mancini et al., 2021; Rodriguez Rodriguez et al., 2021; Sweeney et al., 2021). Microthrombi, which arise in situ in the microvasculature of several organs, have been associated with multiorgan-injury in COVID-19 and are more frequent in patients with arterial hypertension or other comorbidities (Parra-Medina et al., 2021). Several autopsy reports noted the relatively high occurrence of microvascular thrombi in lungs (Ackermann et al., 2020; Carsana et al., 2020; Falasca et al., 2020; Lax et al., 2020; Menter et al., 2020; D’agnillo et al., 2021), heart (Pellegrini et al., 2021; Sang et al., 2021), liver (Rapkiewicz et al., 2020; Kondo et al., 2021), kidney (Rapkiewicz et al., 2020; Akilesh et al., 2021) and the brain (Bryce et al., 2021; Meinhardt et al., 2021; Pajo et al., 2021; Thakur et al., 2021). The finding that VTE, arterial thrombosis and microthrombi co-exist during COVID-19 suggests that these thrombotic events may be driven by several mechanism acting in concert ( $\mathrm{Gu}$ et al., 2021) including altered platelet function (thrombocytopathy) (Manne et al., 2020; Zaid et al., 2020), endothelial dysfunction (endotheliopathy) (Maruhashi and Higashi, 2021), altered complement function (Stenmark et al., 2021), and features underlying immunothrombosis i.e., increased NET formation (Nicolai et al., 2020; Bonaventura et al., 2021). Here, we focus on the contribution of endothelial cells to COVID-19-associated vasculopathies including thrombotic events.

\subsubsection{Clinical Findings of Endothelial Dysfunction in COVID-19 Patients}

Circulating Biomarkers: Multiple biomarkers indicative of endothelial activation and dysfunction have been found to be elevated in COVID-19 patients with a severe disease course
(Lampsas et al., 2021), whereby vascular structural changes have been observed in autopsied organs (Ackermann et al., 2020; Varga et al., 2020; Lee et al., 2021). Pulmonary artery wall thickening due to VSMC hypertrophy, and a decreased lumen size were observed by post-mortem analysis of lungs from COVID-19 patients compared to individuals that were infected with the pandemic $\mathrm{A} / \mathrm{H} 1 \mathrm{~N} 1 / 2009$ influenza virus (Suzuki et al., 2021). However, most of the studies so far suggest that the endothelium participates in the manifestation and severity of COVID-19. For instance, vWF was significantly increased in the plasma of hospitalized COVID-19 patients indicating endothelial activation and a prothrombotic state in severely ill patients (Fraser et al., 2020; Goshua et al., 2020; Pine et al., 2020; Cotter et al., 2021; Thwaites et al., 2021). Other circulating surrogate markers of endothelial activation such as angiopoetin-2, an autocrine antagonist of Tie-2 receptor promoting vessel-destabilizing effects, was found to correlate with COVID-19 severity (Goshua et al., 2020; Pine et al., 2020; Thwaites et al., 2021) and to be predictive for mortality (Pine et al., 2020). Soluble forms of cell adhesion molecules E- and P-selectin also correlated with COVID-19 severity suggesting type-2 endothelial cell activation in patients with more severe disease (Goshua et al., 2020; Pine et al., 2020; Oliva et al., 2021; Thwaites et al., 2021). Several autopsy studies reported vascular inflammation as seen by perivascular immune cell infiltrates in the lung (Ackermann et al., 2020; Aid et al., 2020; Matschke et al., 2020; D'agnillo et al., 2021; Lee et al., 2021; Maccio et al., 2021; Schwabenland et al., 2021) in some of the COVID-19 patients. Sustained endothelial activation and inflammation may lead to endothelial injury during COVID-19 disease course. Along this line, increased circulating glycocalyx degradation products including syndecan-1, chondroitin sulfate and hyaluronic acid were found in COVID-19 patients and were associated with disease severity (Fraser et al., 2020; Queisser et al., 2021). Moreover, increased activity of glycocalyx modifying enzymes such as heparinase and hyaluronidase were measured (Queisser et al., 2021). In addition, increased numbers of circulating endothelial cells, which putatively detached from the vessel wall due to pathological insults, were found to correlate with COVID-19 severity (Guervilly et al., 2020). Interestingly, elevated circulating endothelial cell frequency persisted in recovered convalescent patients suggesting long-term effects of SARSCoV-2 infection on vascular function (Chioh et al., 2021). Endothelial cell detachment and apoptosis lead to exposure of pro-thrombotic mediators such as basement membrane proteins,- and abluminally deposited vWF (Neubauer and Zieger, 2021).

Endothelial Barrier Function: Altered endothelial barrier properties during SARS-CoV-2 infection were observed by the presence of perivascular immune cell infiltrates. In line with this finding, a damaged alveolar capillary barrier was also visualized by discontinuous immunoreactivity of components of endothelial tight junctions and endothelial basement membrane constituents (D'agnillo et al., 2021). Indicative for a compromised blood-brain barrier, fibrinogen leakage into brain parenchyma was seen in more than $50 \%$ of the assessed brains in three case series of COVID-19 patients (Bocci et al., 2021; Lee et al., 2021; 
Schwabenland et al., 2021). Further, assessment of cerebrospinal fluid from COVID-19 patients presenting with neurological symptoms revealed elevated albumin levels, suggesting that impaired blood-brain barrier or blood-cerebrospinal fluid barrier properties may play a role during the COVID-19 disease course (Bernard-Valnet et al., 2021).

Complement System: The complement system is an important part of the innate immune response to bacterial and viral pathogens. Its activation by three different pathways (classical, lectin and alternative) triggers a cascade of enzymatic activation leading to inflammation, phagocytosis and elimination of the pathogen and ultimately results in activation of the adaptive immune response (Merle et al., 2015). Activation of the complement system can also damage endothelial cells, especially if those are already dysfunctional and do not sufficiently express protective, membrane-bound complement regulators (Stenmark et al., 2021). Upregulation of certain complement components in circulation and complement deposition in lung tissue of SARS-CoV-2 infected patients (Cugno et al., 2020; Holter et al., 2020; Magro et al., 2020; Macor et al., 2021) and Rhesus macaques (Aid et al., 2020) were reported. It was shown that SARS-CoV-2 $\mathrm{N}$ protein activates the lectin pathway of complement activation (Flude et al., 2021), while others reported that $\mathrm{N}$ protein does not activate complement, but $\mathrm{S}$ protein activates complement via the alternative pathway (Yu et al., 2020). Interestingly, Ma et al. found that compared to hospitalized patients suffering from influenza virus infection or those with other forms of acute respiratory failure, hospitalized patients with COVID-19 displayed elevated and distinct markers of complement activation (Ma L. et al., 2021). Namely activation via the alternative pathway (as indicated by increased ratio of $\mathrm{iC} 3 \mathrm{~b}$ : $\mathrm{C} 3$, increased factor $\mathrm{B}, \mathrm{sC} 5 \mathrm{~b}$ and $\mathrm{Ba}$ concentrations in plasma) and that an increased activation of the alternative pathway also correlated with worse COVID-19 outcome (Ma L. et al., 2021). These studies suggest that complement activation may contribute to endothelial dysfunction and disease severity in COVID-19 (Stenmark et al., 2021).

Dermal Microvasculature: Higher incidence rates of cutaneous manifestations such as pernio (chilblain)-like acral lesions compared to pre-pandemic times were associated with mild COVID-19 (Agnihothri and Fox, 2021). Pernio-like acral lesions in COVID-19 patients mostly occur on the toes, are characterized by pink papule that develop into violaceous purpuric lesions and are linked to changes in dermal microvasculature resulting in edema and lymphocyte infiltration (Agnihothri and Fox, 2021). These lesions are not to be confused with skin manifestations observed in severe patients with acral livedoid eruptions and retiform purpura, which arise due to a systemic hypercoagulant state (Agnihothri and Fox, 2021; Do et al., 2021).

Together these studies highlight that vascular cell dysfunction is not only limited to the lung, but the complete COVID-19 pathogenesis shows that the vasculature of multiple other organs are affected as well (Figure 3). However, the specific mechanisms inducing aberrant endothelial function at the different tissue sites only begin to be elucidated. Whether cytopathogenic effects driven by direct endothelial infection with SARS-CoV-2 play a role and which immune-mediated mechanisms are primarily inducing endothelial pathology during COVID-19 is a matter of current investigations. Moreover, whether infection of other vascular cells such as pericytes, VSMC or vascular fibroblasts occurs and contributes to endotheliopathy during COVID-19 is still unclear and needs to be further investigated.

\subsection{ACE2 Expression in Vascular Cells in Situ}

The current consensus is that the cell surface expression of ACE2 (and the host protease TMPRSS2) is the main determinant for the cellular tropism of SARS-CoV-2, although additional coreceptors and a number of alternative entry receptors have been proposed (Baggen et al., 2021). Meta-analysis of various recent single-cell RNAseq datasets of mouse brain, heart and lung identified pericytes and certain VSMC populations as the only vascular cell types expressing ACE2, which was corroborated by immunofluorescent analyses, however this data is still preliminary (He et al., 2020). Notably, TMPRSS2 was not detected in the ACE2-positive mural cell types (He et al., 2020). Other investigators also found, by single-cell RNAseq of mouse brain and high-resolution microscopy of cerebral microvessels, that pericytes are the predominant vascular cell type expressing ACE2 (Wenzel et al., 2021). Similarly, in human heart single-cell and single-nucleus RNAseq data sets, pericytes expressed ACE2, while endothelial cells did not (Chen et al., 2020). A meta-analysis of a big number of single-cell and singlenucleus RNAseq data sets from various human tissues revealed that neither endothelial cells nor pericyte and VSMC co-express ACE2 and TMPRSS2 (Muus et al., 2021). Strikingly, endothelial cells showing ACE2 expression also expressed markers of pericytes, suggesting technical difficulties in the separation of endothelial cells from pericytes for transcriptomic analyses and insufficient separation could introduce false-positive ACE2expression in endothelial cells (Mccracken et al., 2021). While results from RNAseq studies rather point to an absence of ACE2expression in endothelial cells, several histology-based studies in human post-mortem samples demonstrated scattered expression of ACE2 in presumably endothelial cells. For instance, positive ACE2-immunoreactivity was observed in pulmonary microvascular endothelial cells (Wong et al., 2021) and increasingly with smaller vessel size in the heart (Maccio et al., 2021). ACE2-positive brain microvascular endothelial cells were found in the basal ganglia of COVID-19 and control patients (Kirschenbaum et al., 2021), in the Medulla Oblongata (Meinhardt et al., 2021) and in the frontal cortex predominantly in patients that suffered from dementia or hypertension (Buzhdygan et al., 2020). None of these studies unequivocally showed that vascular ACE2-immunoreactivity indeed stems from endothelial cells, instead the signal could also be pericyte derived. In line, in islet and exocrine capillaries of the human pancreas, ACE2-expression was detected in pericytes (Coate et al., 2020). Another very recent report showed that ACE2 immunolabelling in microvessels of the human frontal cortex coincided with the pericyte marker 
PDGFR- $\beta$ and not endothelial CD31 (Bocci et al., 2021). Altogether, expression of ACE2 by endothelial cells is still a matter of debate and whether ACE2 expression in endothelial cells and pericytes differs in various vascular beds, position along the vascular tree or certain (pathological) conditions needs to be investigated in more detail (Figure 3).

\subsection{Are Endothelial Cells Directly Infected by SARS-CoV-2 in Vivo?}

In primary sites of infection such as the alveoli, SARS-CoV-2 can reach the lung capillaries at the air-blood barrier from the abluminal side in case of disruption of the alveolar epithelial cell layer. In distant organs endothelial cells can only be targeted by viral infection from the luminal side in case of hematogenous virus spread. Viral RNA in blood (serum or plasma) in COVID-19 patients has been detected most prominently in more severely ill patients (Bermejo-Martin et al., 2020) and blood RNA levels could act as predictor for disease outcome (Li Y. et al., 2021; Hogan et al., 2021; Jacobs et al., 2021; Rodríguez-Serrano et al., 2021). However, it has not been confirmed that viral RNA found in blood also stems from active virions or rather from RNA fragments (Andersson et al., 2020).

Early post-mortem studies suggested that endothelial cell dysfunction in the lung and kidney is directly caused by endothelial cell infection with SARS-CoV-2 (Ackermann et al., 2020; Varga et al., 2020). S protein positivity in CD34 ${ }^{+}$cells lining pulmonary vessels, in presumably endothelial cells of the renal glomeruli and the seminiferous tubules was reported (Yao et al., 2021). Co-expression of ACE2 and SARS-CoV-2 spike mRNA was observed by in situ hybridization in microvascular cells in the lung of some COVID-19 patients (Wong et al., 2021). Interestingly (D'agnillo et al., 2021), reported infrequent $\mathrm{N}$-protein immunoreactivity in endothelial cells and pericytes of small and medium sized pulmonary vessels exclusively in COVID-19 patients with high viral load and a short time interval between symptom onset and death (D'agnillo et al., 2021). A study employing imaging mass spectrometry of lung sections from COVID-19 deceased patients found S protein positive VSCMs (Rendeiro et al., 2021) indicating that VSMCs could also be a cellular target of SARS-CoV-2. In contrast, other studies reported no detection of SARS-CoV-2 proteins/RNA in pulmonary vessels (Schaefer et al., 2020; Massoth et al., 2021), neither were SARS-CoV-2 proteins detected at any time point in pulmonary vasculature of infected Syrian gold hamsters (Allnoch et al., 2021). In the heart of COVID-19 patients, independent of the occurrence of microthrombi, infected endothelial cells could not be observed, but low numbers of infected myocytes were found (Pellegrini et al., 2021). In contrast, another study that detected clinically relevant SARS-CoV-2 transcripts in 41/95 autopsied hearts, reported the more frequent detection of $\mathrm{N}$ protein in ICAM- $1^{+}$endothelial cells than in alpha-actinin ${ }^{+}$ cardiomyocytes (Brauninger et al., 2021). In brain autopsy case series of COVID-19 deceased patients, detection of viral protein or RNA in brain capillaries in various brain regions such as the brain stem and the olfactory bulb were found in a very low number of patients (Bhatnagar et al., 2021; Meinhardt et al., 2021; Nuovo et al., 2021; Schwabenland et al., 2021; Song et al., 2021).
In summary, viral entry into endothelial cells of (micro)vessels in multiple organs is not a widely observed phenomenon. Since some of the mentioned studies do not use multicolor staining, it is unclear, whether identified viral proteins or RNA are really located in endothelial cells or rather in mural cells, as shown in Figure 3. Another confounding factor is the specificity of antibodies used to detect viral proteins, namely several groups have reported inconclusive results due to positive staining in control tissues (Yang A. C. et al., 2021; Meinhardt et al., 2021; Wong et al., 2021).

\subsection{In Vitro Infection of Endothelial Cells With SARS-CoV-2 \\ 4.5.1 Static Cell Cultures}

Observations in the vasculature of COVID-19 patients triggered research on endothelial cells in vitro to shed light on the possibility of direct viral infection of endothelial cells by SARS-CoV-2. Most of these studies have applied static monolayer cultures of primary human endothelial cells derived from different anatomical locations of the human body using inoculums to initiate the viral infection. For instance, endothelial cell types such as umbilical vein endothelial cells (HUVECs), blood outgrowth and aortic endothelial cells, as well as lung-, brain-, cardiac- and glomerular microvascular endothelial cells, were subjected to viral infection, however, none of these cell were susceptible to direct infection by SARS-CoV-2 (Nascimento Conde et al., 2020; Ahmetaj-Shala et al., 2020). Others showed marginal viral replication in coronary artery endothelial cells after 5 days of infection (Wagner et al., 2021). Moreover, in an established human blood-brain barrier model where CD34 ${ }^{+}$ umbilical cord blood-derived endothelial cells were grown on filter inserts in co-culture with bovine pericytes, no productive infection of endothelial cells was detected. Also, no impairment of their barrier function was observed, and an inflammatory response remained absent, indicating that these brain-like endothelial cells were not affected by infection with SARSCoV-2 (Constant et al., 2021). In contrast, although active viral replication remained absent in primary lung endothelial cells, an inflammatory response was induced during SARS-CoV-2 infection, indicating that there is an interaction between primary lung endothelial cells and the virus (Caccuri et al., 2021).

Since direct viral infection of endothelial cells in vitro under static conditions is unlikely, as shown in Figure 3, other methods have been applied to make endothelial cells susceptible. One method to infect endothelial cells is to transduce brain- and pulmonary-derived endothelial cells with lentiviruses containing the coding sequence of ACE2, indicating that efficient replication in these cells is possible, but overexpression of ACE2 is required (Nascimento Conde et al., 2020) (Figure 3). Another study has shown with nonphysiological inoculums of 10 and 100 multiplicity of infection (MOI) that pulmonary and cardiac endothelial cells show minimal viral replication due to low ACE2 expression (Mccracken et al., 2021). However, infection with these unnatural high amounts of infectious virus particles raises the question if one is still investigating normal entry of the 
virus or if this might be enforced by alternative pathways like macropinocytosis (de Vries et al., 2011).

\subsubsection{More Advanced in Vitro and Co-culture Systems}

As the infection of static monolayers of endothelial cells was proven to be inefficient, alternative cell culture methods have been applied as well. For instance, transwell filter systems allow for initiation of the viral infection via different compartments, namely apical and basolateral. The study of Schimmel et al. (2021) showed that the virus cannot actively replicate in umbilical cord and microvascular endothelial cells, but SARSCoV-2 is able to enter the cell via either the apical or basolateral side (Schimmel et al., 2021). Moreover, a pro-inflammatory response of the cells was observed, indicative of an interaction of the virus with the cells. In addition, the endothelial cells are exposed to shear stress in vivo, and therefore employing microfluidic devices is a potentially interesting technique mimicking the natural vascular environment. Endothelial cells that were seeded in a polydimethylsiloxane (PDMS) channel containing a collagen hydrogel were infected under flow, but also this method did not allow for viral replication of SARS-CoV-2 in the endothelial cells (Schimmel et al., 2021). This is an interesting finding since it has been described that shear stress could upregulate ACE2 expression in brain microvascular endothelial cells, thereby allowing for attachment of the $S$ protein, as shown in (Kaneko et al., 2021) Figure 3.

Another approach is the human lung-on-a-chip model which allows for the culturing of cells in different compartments in an air-liquid interface (ALI, Figure 3). It has been shown for instance that human type I and II alveolar epithelial cells could be cultured in the apical compartment under ALI, while in the basolateral compartment endothelial cells were seeded and exposed to a pulsatile flow (Thacker et al., 2021). Viral infection of the alveolar cells had a direct effect on the endothelial cells by disrupting the confluent cell layer integrity after 3 days of infection, whereby the $S$ protein could be observed in both cell types but viral replication remained absent (Thacker et al., 2021). A different lung-on-a-chip model showed that epithelial cells elicit an inflammatory response after $28 \mathrm{~h}$ of infection, while the endothelial chamber did not show a positive signal for the staining of the S protein (Deinhardt-Emmer et al., 2021). Also, the endothelial cell layer remained intact, indicating that these cells were not affected by the infected epithelial cells (DeinhardtEmmer et al., 2021).

In the vascular wall endothelial cells are accompanied by other cell types like smooth muscle cells and pericytes. Currently, there is minimal knowledge if other vascular cell types play a role in the clinical manifestations in COVID-19-patients, despite their expression of the ACE2 receptor (Hamming et al., 2004; He et al., 2020; Nicin et al., 2020). However, one hypothesis is that the junction leakage of the endothelium is due to the infection of vascular pericytes, which secrete secondary signals that induce activation of microvascular endothelial cells ( $\mathrm{He}$ et al., 2020). It has been described that iPSC-derived brain pericyte-like cells are susceptible to infection with SARS-CoV-2 whereby viral replication is observed over $72 \mathrm{~h}$ (Wang L. et al., 2021). Moreover, iPSC-derived blood vessel organoids containing endothelial cells and pericytes were infected with SARS-CoV-2 and viral replication could be observed on a transcriptional level after 3- and 6-days post infection (Monteil et al., 2020) (Figure 3). Primary human pericytes and astrocytes were directly infected without exhibiting any successful viral replication and cytopathogenic effects (Constant et al., 2021). Altogether, more research should be performed on cells that are present in the vascular wall and perivascular locations since these can have an immense effect on the surrounding tissue, including endothelial cells.

In summary, although the endothelium is severely affected in vivo in COVID-19 patients, these observations could not be reenacted in vitro in static cell cultures, and more complex cell culture systems in the form of microfluidic channels or lung-ona-chip models need to be used to detect vascular cell damage or -activation by SARS-CoV-2. In addition, co-cultures of endothelial cells with pericytes showed viral replication, indicating that other cells present in the vascular wall, or the perivascular environment might be susceptible for viral infection and that endothelial cells respond to secondary signals secreted from these infected cells. In this context, the route of infection necessitates consideration. In a situation in which SARS-CoV-2 reaches the vessel via the blood, infection of vascular wall- and perivascular cells would require an endothelial barrier deficiency allowing virus to gain access to these abluminal cell types.

\subsubsection{In Vitro Investigations of Indirect Mechanisms Affecting Endothelial Function}

Recent in vivo and in vitro findings suggest that direct infection of endothelial cells is rather unlikely. Indirect mechanisms because of epithelial cell infection and exuberated inflammation can play a more important role in causing endothelial damage in COVID-19 (Figure 3). To this end, plasma-induced cytotoxicity in pulmonary vascular endothelial cells $1 \mathrm{~h}$ after treatment was assessed and correlated with disease severity and concentration of circulating markers of endothelial damage and organ dysfunction (Rauch A. et al., 2020). Another study did not observe cytotoxicity upon treatment of HUVECs with plasma from hospitalized COVID-19 patients, but observed increased glycocalyx shedding. Concomitantly these COVID-19 plasma samples exhibited elevated heparinase I level (Potje et al., 2021). Treatment of pulmonary microvascular endothelial cells for $16 \mathrm{~h}$ with plasma from hospitalized COVID-19 patients induced dysregulated biosynthesis and degradation of endothelial hyaluronic acid. The resulting shift towards lower molecular weight hyaluronic acid fragments in the medium reduced barrier properties of the endothelial cells (Queisser et al., 2021). In contrast, the permeability of brain-like endothelial cells was not changed after $48 \mathrm{~h}$ treatment with plasma from COVID-19 patients that developed severe disease (Constant et al., 2021). In severe COVID-19, platelet hyperactivation is often observed (Manne et al., 2020; Zaid et al., 2020), and treatment of endothelial cells with supernatant of activated platelets induced a strong upregulation of pro-inflammatory and procoagulant pathways as assessed by RNAseq. This effect was attributed to the significantly increased transcription of S100A8/A9 in platelets of COVID-19 patients and circulating levels of its protein product 
MRP8/14, a known pro-inflammatory heterodimer secreted by activated platelets and neutrophils, was also found to correlate with COVID-19 severity (Barrett et al., 2021).

In summary, these studies show that indirect effects of SARSCoV-2 infection mediated through plasma can be observed also in cultured endothelial cells, highlighting the importance of employing more sophisticated culture system that mimic certain physiological features.

\section{LONG-COVID SYNDROME (LCS) IN CVD}

Around $40-45 \%$ of SARS-CoV-2 infections in humans remain symptom free (Oran and Topol, 2020). However, $60-80 \%$ of the patients discharged from the hospital have reported at least one residual symptom 50 days after testing positive for SARS-CoV-2 (Carfi et al., 2020; Halpin et al., 2021) and 35\% of non-hospitalized individuals reported symptoms 14-21 days after initial diagnosis (Tenforde et al., 2020). Hence, more attention needs to be paid to the potential for long-term complications in patients diagnosed with COVID-19. The term long-Covid Syndrome (LCS) includes a number of different terms such as "Post-acute COVID-19" and "Post-COVID-19 syndrome". The latter are distinguished according to their duration, into "Post-acute COVID-19", describing patients who still have symptoms after 4-12 weeks, while patients with symptoms after more than 12 weeks are classified under the "Post-COVID-19 syndrome" (Venkatesan, 2021). The most described symptoms for LCS are fatigue, headache, attention deficit, hair loss, and shortness of breath. In addition, chest pain, palpitations, and tachycardia have also been described, as well as depression and neurologic impairment and dysfunction (Nalbandian et al., 2021). According to current knowledge, these symptoms may persist for months and are also found in patients with mild disease courses (Lopez-Leon et al., 2021; Venkatesan, 2021). With respect to cardiovascular complications studies in deceased COVID-19 patients revealed arterial and venous thromboembolism, strongly suggesting that SARS-CoV-2 negatively affects the vasculature throughout the body with so far largely unknown long-term consequences.

\subsection{Long Term Consequences of COVID-19 on the Heart}

In the context of CVD, chest pain is the most described symptom in patients with prior COVID-19 regardless of severity. Case numbers vary from 5 to $21 \%$ two to six months after disease onset with a decreasing trend the longer the disease has been diagnosed (Carvalho-Schneider et al., 2021; Romero-Duarte et al., 2021). Palpitations are also reported with a frequency of about $10 \%$ two to six months after COVID-19 diagnosis (Huang et al., 2021; Romero-Duarte et al., 2021) and heartbeat irregularities have raised the question of a more frequent occurrence of arrhythmias after COVID-19. Patients who required ICU treatment had an enhanced average risk of developing acute arrhythmia (Coromilas et al., 2021), but there have been no conclusive studies as to whether these arrhythmias persist in the setting of LCS (longer than 3 months). Palpitations may also indicate tachycardia, but the data on LCS are still limited (Blitshteyn and Whitelaw, 2021), especially since previous studies on e.g., QT interval (time taken for ventricular depolarization and repolarization) changes were also performed in patients receiving drugs that affect these intervals (e.g., chloroquine) (O'connell et al., 2021). COVID-19 patients were also associated with a higher risk of myocardial damage and myocarditis, as magnetic resonance imaging (MRI) screenings revealed pathologic changes in both hospitalized patients and those with mild courses. These changes included increased T1 (spin-lattice relaxation time) and T2 (spin-spin relaxation time) values (associated with heart damage) as well as late gadolinium enhancement (LGE) as retrieved from analysis 30-70 days after COVID-19 diagnosis (Knight et al., 2020; Puntmann et al., 2020). The longest follow-up study was performed 189 days after diagnosis of COVID-19 in 74 patients, but the number of patients with pathologic MRI was very low at that point and T1, T2 and LGE were not significantly changed in this group compared to healthy subjects (Joy et al., 2021). However, the values of affected patients vary widely, which is certainly due to small study cohorts, among other factors (Knight et al., 2020; Puntmann et al., 2020; Kotecha et al., 2021; Pan et al., 2021). Reports with more than 100 patients and analyses for more than 1 month after COVID-19 diagnosis are rare and almost absent for more than 1,000 patients. Therefore, a large study with 1,597 athletes 1 month after COVID-19 diagnosis should be highlighted here. Myocarditis (mostly asymptomatic) was detected in $2.3 \%$ of the patients and no significant change in $\mathrm{T}$ relaxation time-values was reported (Daniels et al., 2021). Athletes deserve special attention because in this group even a slight decrease in cardiac function, which would be asymptomatic in normal individuals, has a significant impact on performance. Another, population-based analysis, of approximately 35,000 young Americans of both sexes aged 12-19years revealed a mean myocarditis rate of $0.08 \%$. Around $60 \%$ of these cases were diagnosed 19-82 days after infection, however this data is still preliminary (Singer et al., 2021).

In addition, studies have also shown a correlation of elevated serum troponin levels and a higher risk of myocardial injury and substantially higher mortality in COVID-19 patients (Knight et al., 2020; Shi et al., 2020; Wei et al., 2020; Caro-Codón et al., 2021). Notably, in a large study with 1,053 patients with COVID-19 in whom troponin-I, B-type natriuretic peptide, C-reactive protein, ferritin, and D-dimer were measured, only troponin was identified as the only independent predictor of 30-days mortality (Manocha et al., 2021). Nevertheless, earlier studies with a smaller number of patients did report significant changes in D-dimer after an average of 80 days post COVID-19 diagnosis and increases seemed to be more common in hospitalized patients older than 50 years (Townsend et al., 2021; Von Meijenfeldt et al., 2021).

\subsection{Long Term Consequences of COVID-19 on the Vasculature}

Data on long term consequences of COVID-19 disease on vascular function are even more scarce than studies on the heart. Early on during the pandemic researchers learned that acute COVID-19 is associated with severe pulmonary and extrapulmonary vascular inflammation, both on the macro- and microvascular level 
(Ackermann et al., 2020). In addition, pulmonary and extrapulmonary thromboembolism are common complications, determining initial and maybe also long-term consequences of COVID-19 disease (Madjid et al., 2020). Moreover, some cases of a type 3 hypersensitivity reaction were reported to contribute to vascular inflammation in COVID-19 patients (Roncati et al., 2020) and the highly proinflammatory cytokine response initiated by SARS-CoV-2 is also believed to cause endothelial damage (Cao, 2020). Cytokines like TNF- $\alpha$ and IL- $1 \beta$ are well known for their proinflammatory effects on the endothelium and may play a key role in vascular dysfunction in COVID-19 (Norooznezhad and Mansouri, 2021). However, only a few studies with small cohort sizes investigated the long-term impact of COVID-19 on the vasculature. Sollini et al. (2021) evaluated if 2-deoxy-2-[18F] fluoro-D-glucose ([18F]FDG) was able to mark persistent inflammation by examining 10 COVID-19 patients with persisting symptoms for more than 30 days. Imaging was done by $[18 \mathrm{~F}] \mathrm{FDG}$ positron emission tomography/computed tomography ([18F]FDG-PET/CT) and showed that the total vascular score was similar in the two groups. However, the target-to-blood pool ratio was significantly higher in three vascular regions (thoracic aorta, right iliac artery, and femoral arteries) in the recovered cohort compared to the control group, arguing for a persisting vascular inflammation. The authors further suggest that the distinct feature (smooth linear pattern) of [18F]FDG vascular uptake in LCS was similar to that observed in large vessel vasculitis (Sollini et al., 2021). Analysis of acute phase markers, endothelial cell activation, NET formation, and thrombin generation in 50 patients 68 days after confirmed SARS-CoV-2 infection showed sustained endothelial cell activation up to 10 weeks following acute SARS-CoV-2 infection (Fogarty et al., 2021). These data further suggest that endothelial dysfunction occurs independently of ongoing acute phase response or NET formation but is associated with enhanced thrombin generation. The authors further hypothesize that shedding of thrombin from endothelial cells may play a role in modulating the loss of normal endothelial cell quiescence (Fogarty et al., 2021). Others investigated the potential effects of SARS-CoV-2 on the systemic vasculature in the arms and legs, examining 20 young adults. Using a crosssectional design, these two studies assessed vascular function 3-4 weeks after SARS-CoV-2 infection by Doppler ultrasound measuring flow mediated dilation (FMD) in the arm and single passive limb movement in the leg. In addition, carotid-femoral pulse wave velocity was assessed as a marker of arterial stiffness. Results demonstrated significantly lower systemic vascular function and higher arterial stiffness in participants testing positive for SARSCoV-2 compared with controls. These studies included male and female participants but did not see sex specific effects (Ratchford et al., 2021; Szeghy et al., 2021). In a similar study design but with a longer follow up (3 months from diagnosis of COVID-19) 16 young adults were investigated for brachial FMD, cerebral vasodilator function and arterial stiffness. Out of these 16 participants, eight were still symptomatic while the others did no longer display signs of COVID-19. Subsequent analysis revealed that peripheral macrovascular and microvascular vasodilation was significantly reduced in young adults still being symptomatic, while asymptomatic participants had similar vascular function compared with controls. Cerebral vascular function and central arterial stiffness were unaffected irrespective of COVID-19 symptoms persisting or not (Nandadeva et al., 2021).

In summary, because of the high rate of clinically significant cardiovascular events during acute COVID-19, long-term adverse events are expected (Nalbandian et al., 2021) (Figure 2). However, these need to be better understood, studied in larger cohorts, and most importantly, observed over a longer period of time after infection to better distinguish between effects that resolve after 3-12 months or truly result in chronic disease.

\section{SUMMARY AND CONCLUSION}

Taken together, clinical manifestations of SARS-CoV-2 infection have been detected in several vascular beds (e.g., those of the lungs, heart, and kidneys) and are not restricted to the pulmonary system. According to current research, direct viral infection of cardiomyocytes and pericytes together with dysfunctional endothelium foster vascular dysfunction in COVID-19 patients. Endothelial cells, putatively not prone to direct viral infection through SARS-CoV-2, probably get indirectly activated via the inflammatory immune response ("cytokine storm") mediated by the virus. In addition, pre-existing CVD renders COVID-19 patients particularly vulnerable for downstream vascular complications and COVID-19-associated mortality. Altogether, chronic inflammation and vascular damage contribute to the acute pathophysiology of COVID-19 but may also cause development of LCS.

Currently, significant efforts are being made to decipher both the direct and indirect impact of SARS-CoV-2 on the vasculature. In vitro studies, for example of endothelial cells, pericytes and cardiomyocytes have already shed some light on how SARS-CoV2 directly affects vascular cells and explored which downstream signaling events are involved. Yet, only limited conclusions on the contribution of immune cells to vascular dysfunction during SARS-CoV-2 infection can be drawn. More complex cell culture/organoid systems to better exploit and resemble the complex nature of cell-cell interactions need to be established in vitro. To complement these in vitro studies and allow for exploration of long-term consequences of dysfunctional vasculature in COVID-19 well-defined in vivo models need to be investigated. Hence, combined efforts are required to comprehend the varied responses to SARS-CoV-2 infection to pave the way for new treatment strategies, including those for the long-term cardiovascular effects of COVID-19.

\section{AUTHOR CONTRIBUTIONS}

All authors drafted the manuscript and made critical revisions.

\section{FUNDING}

This research was funded by the Swiss National Science Foundation (SNSF) within the National Research Program NRP 78, project ID 4078P0_198297 to YD, BE, NM, and RR. 


\section{REFERENCES}

Ackermann, M., Verleden, S. E., Kuehnel, M., Haverich, A., Welte, T., Laenger, F., et al. (2020). Pulmonary Vascular Endothelialitis, Thrombosis, and Angiogenesis in Covid-19. N. Engl. J. Med. 383, 120-128. doi:10.1056/ nejmoa2015432

Affinati, A. H., Wallia, A., and Gianchandani, R. Y. (2021). Severe Hyperglycemia and Insulin Resistance in Patients with SARS-CoV-2 Infection: a Report of Two Cases. Clin. Diabetes Endocrinol. 7, 8. doi:10.1186/s40842-021-00121-y

Agnihothri, R., and Fox, L. P. (2021). Clinical Patterns and Morphology of COVID-19 Dermatology. Dermatol. Clin. 39, 487-503. doi:10.1016/j.det. 2021.05.006

Ahmetaj-Shala, B., Peacock, T. P., Baillon, L., Swann, O. C., Gashaw, H., Barclay, W. S., et al. (2020). Resistance of Endothelial Cells to SARS-CoV-2 Infection In Vitro. bioRxiv 2020, 372581. doi:10.1101/2020.11.08.372581

Ahn, J. H., Kim, J., Hong, S. P., Choi, S. Y., Yang, M. J., Ju, Y. S., et al. (2021). Nasal Ciliated Cells Are Primary Targets for SARS-CoV-2 Replication in the Early Stage of COVID-19. J. Clin. Invest. 131, e148517. doi:10.1172/JCI148517

Aid, M., Busman-Sahay, K., Vidal, S. J., Maliga, Z., Bondoc, S., Starke, C., et al. (2020). Vascular Disease and Thrombosis in SARS-CoV-2-Infected Rhesus Macaques. Cell 183, 1354-1366. e1313. doi:10.1016/j.cell.2020.10.005

Aird, W. C. (2012). Endothelial Cell Heterogeneity. Cold Spring Harbor Perspect. Med. 2, a006429. doi:10.1101/cshperspect.a006429

Akarsu, C., Karabulut, M., Aydin, H., Sahbaz, N. A., Dural, A. C., Yegul, D., et al. (2020). Association between Acute Pancreatitis and COVID-19: Could Pancreatitis Be the Missing Piece of the Puzzle about Increased Mortality Rates? J. Invest. Surg. 35 (1), 119-125. doi:10.1080/08941939.2020.1833263

Akilesh, S., Nast, C. C., Yamashita, M., Henriksen, K., Charu, V., Troxell, M. L., et al. (2021). Multicenter Clinicopathologic Correlation of Kidney Biopsies Performed in COVID-19 Patients Presenting with Acute Kidney Injury or Proteinuria. Am. J. Kidney Dis. 77, 82-93. e81. doi:10.1053/j.ajkd.2020. 10.001

Allnoch, L., Beythien, G., Leitzen, E., Becker, K., Kaup, F. J., Stanelle-Bertram, S., et al. (2021). Vascular Inflammation Is Associated with Loss of Aquaporin 1 Expression on Endothelial Cells and Increased Fluid Leakage in SARS-CoV-2 Infected Golden Syrian Hamsters. Viruses 13, 639. doi:10.3390/v13040639

Andersson, M. I., Arancibia-Carcamo, C. V., Auckland, K., Baillie, J. K., Barnes, E., Beneke, T., et al. (2020). SARS-CoV-2 RNA Detected in Blood Products from Patients with COVID-19 Is Not Associated with Infectious Virus. Wellcome Open Res. 5, 181. doi:10.12688/wellcomeopenres.16002.1

Augusto, G., Mohsen, M. O., Zinkhan, S., Liu, X., Vogel, M., and Bachmann, M. F. (2021). In Vitro data Suggest that Indian delta Variant B.1.617 of SARS-CoV-2 Escapes Neutralization by Both Receptor Affinity and Immune Evasion. Allergy 77 (1), 111-117. doi:10.1111/all.15065

Baggen, J., Vanstreels, E., Jansen, S., and Daelemans, D. (2021). Cellular Host Factors for SARS-CoV-2 Infection. Nat. Microbiol. 6, 1219-1232. doi:10.1038/ s41564-021-00958-0

Barlev-Gross, M., Weiss, S., Ben-Shmuel, A., Sittner, A., Eden, K., Mazuz, N., et al. (2021). Spike vs Nucleocapsid SARS-CoV-2 Antigen Detection: Application in Nasopharyngeal Swab Specimens. Anal. Bioanal. Chem. 413, 3501-3510. doi:10.1007/s00216-021-03298-4

Barrett, T. J., Cornwell, M., Myndzar, K., Rolling, C. C., Xia, Y., Drenkova, K., et al. (2021). Platelets Amplify Endotheliopathy in COVID-19. Sci. Adv. 7, eabh2434. doi:10.1126/sciadv.abh2434

Bazzan, M., Montaruli, B., Sciascia, S., Cosseddu, D., Norbiato, C., and Roccatello, D. (2020). Low ADAMTS 13 Plasma Levels Are Predictors of Mortality in COVID-19 Patients. Intern. Emerg. Med. 15, 861-863. doi:10.1007/s11739-02002394-0

Bean, D. M., Kraljevic, Z., Searle, T., Bendayan, R., Kevin, O. G., Pickles, A., et al. (2020). Angiotensin-converting Enzyme Inhibitors and Angiotensin II Receptor Blockers Are Not Associated with Severe COVID-19 Infection in a Multi-Site UK Acute Hospital Trust. Eur. J. Heart Fail. 22 (6), 967-974. doi:10. 1002/ejhf.1924

Berger, J. S., Kunichoff, D., Adhikari, S., Ahuja, T., Amoroso, N., Aphinyanaphongs, Y., et al. (2020). Prevalence and Outcomes of D-Dimer Elevation in Hospitalized Patients with COVID-19. Atvb 40, 2539-2547. doi:10. 1161/atvbaha.120.314872
Berlin, D. A., Gulick, R. M., and Martinez, F. J. (2020). Severe Covid-19. N. Engl. J. Med. 383, 2451-2460. doi:10.1056/nejmcp2009575

Bermejo-Martin, J. F., González-Rivera, M., Almansa, R., Micheloud, D., Tedim, A. P., Domínguez-Gil, M., et al. (2020). Viral RNA Load in Plasma Is Associated with Critical Illness and a Dysregulated Host Response in COVID-19. Crit. Care 24, 691. doi:10.1186/s13054-020-03398-0

Bernard-Valnet, R., Perriot, S., Canales, M., Pizzarotti, B., Caranzano, L., CastroJiménez, M., et al. (2021). Encephalopathies Associated with Severe COVID-19 Present Neurovascular Unit Alterations without Evidence for Strong Neuroinflammation. Neurol. Neuroimmunol Neuroinflamm 8, e1029. doi:10. 1212/nxi.0000000000001029

Beyerstedt, S., Casaro, E. B., and Rangel, É. B. (2021). COVID-19: AngiotensinConverting Enzyme 2 (ACE2) Expression and Tissue Susceptibility to SARSCoV-2 Infection. Eur. J. Clin. Microbiol. Infect. Dis. 40, 905-919. doi:10.1007/ s10096-020-04138-6

Bhatnagar, J., Gary, J., Reagan-Steiner, S., Estetter, L. B., Tong, S., Tao, Y., et al. (2021). Evidence of Severe Acute Respiratory Syndrome Coronavirus 2 Replication and Tropism in the Lungs, Airways, and Vascular Endothelium of Patients with Fatal Coronavirus Disease 2019: An Autopsy Case Series. J. Infect. Dis. 223, 752-764. doi:10.1093/infdis/jiab039

Blitshteyn, S., and Whitelaw, S. (2021). Postural Orthostatic Tachycardia Syndrome (POTS) and Other Autonomic Disorders after COVID-19 Infection: a Case Series of 20 Patients. Immunol. Res. 69, 205-211. doi:10. 1007/s12026-021-09185-5

Bocci, M., Oudenaarden, C., Sàenz-Sardà, X., Simrén, J., Edén, A., Sjölund, J., et al. (2021). Infection of Brain Pericytes Underlying Neuropathology of COVID-19 Patients. Int. J. Mol. Sci. 22, 11622. doi:10.3390/ijms222111622

Bojkova, D., Wagner, J. U. G., Shumliakivska, M., Aslan, G. S., Saleem, U., Hansen, A., et al. (2020). SARS-CoV-2 Infects and Induces Cytotoxic Effects in Human Cardiomyocytes. Cardiovasc. Res. 116, 2207-2215. doi:10.1093/cvr/cvaa267

Bonaventura, A., Vecchié, A., Dagna, L., Martinod, K., Dixon, D. L., Van Tassell, B. W., et al. (2021). Endothelial Dysfunction and Immunothrombosis as Key Pathogenic Mechanisms in COVID-19. Nat. Rev. Immunol. 21, 319-329. doi:10.1038/s41577-021-00536-9

Booth, A., Johnson, D. R., Granger, D. A., Crouter, A. C., and Mchale, S. (2003). Testosterone and Child and Adolescent Adjustment: the Moderating Role of Parent-Child Relationships. Developmental Psychol. 39, 85-98. doi:10.1037/ 0012-1649.39.1.85

Braun, F., Lütgehetmann, M., Pfefferle, S., Wong, M. N., Carsten, A., Lindenmeyer, M. T., et al. (2020). SARS-CoV-2 Renal Tropism Associates with Acute Kidney Injury. The Lancet 396, 597-598. doi:10.1016/s0140-6736(20)31759-1

Brauninger, H., Stoffers, B., Fitzek, A. D. E., Meissner, K., Aleshcheva, G., Schweizer, M., et al. (2021). Cardiac SARS-CoV-2 Infection Is Associated with Pro-inflammatory Transcriptomic Alterations within the Heart. Cardiovasc. Res. 1, cvab322. doi:10.1093/cvr/cvab322

Bristow, M. R., Zisman, L. S., Altman, N. L., Gilbert, E. M., Lowes, B. D., Minobe, W. A., et al. (2020). Dynamic Regulation of SARS-Cov-2 Binding and Cell Entry Mechanisms in Remodeled Human Ventricular Myocardium. JACC: Basic Translational Sci. 5, 871-883. doi:10.1016/j.jacbts.2020.06.007

Bryce, C., Grimes, Z., Pujadas, E., Ahuja, S., Beasley, M. B., Albrecht, R., et al. (2021). Pathophysiology of SARS-CoV-2: the Mount Sinai COVID-19 Autopsy Experience. Mod. Pathol. 34, 1456-1467. doi:10.1038/s41379021-00793-y

Burkhard-Koren, N. M., Haberecker, M., Maccio, U., Ruschitzka, F., Schuepbach, R. A., Zinkernagel, A. S., et al. (2021). Higher Prevalence of Pulmonary Macrothrombi in SARS-CoV-2 Than in Influenza A: Autopsy Results from 'Spanish Flu' 1918/1919 in Switzerland to Coronavirus Disease 2019. J. Pathol. Clin. Res. 7, 135-143. doi:10.1002/cjp2.189

Buzhdygan, T. P., Deore, B. J., Baldwin-Leclair, A., Bullock, T. A., Mcgary, H. M., Khan, J. A., et al. (2020). The SARS-CoV-2 Spike Protein Alters Barrier Function in 2D Static and 3D Microfluidic In-Vitro Models of the Human Blood-Brain Barrier. Neurobiol. Dis. 146, 105131. doi:10.1016/j.nbd.2020. 105131

Caccuri, F., Bugatti, A., Zani, A., De Palma, A., Di Silvestre, D., Manocha, E., et al. (2021). SARS-CoV-2 Infection Remodels the Phenotype and Promotes Angiogenesis of Primary Human Lung Endothelial Cells. Microorganisms 9, 1438. doi:10.3390/microorganisms 9071438 
Cameroni, E., Bowen, J. E., Rosen, L. E., Saliba, C., Zepeda, S. K., Culap, K., et al. (2021). Broadly Neutralizing Antibodies Overcome SARS-CoV-2 Omicron Antigenic Shift. Nature 1, 1. doi:10.1038/d41586-021-03825-4

Cao, X. (2020). COVID-19: Immunopathology and its Implications for Therapy. Nat. Rev. Immunol. 20, 269-270. doi:10.1038/s41577-020-0308-3

Carfi, A., Bernabei, R., and Landi, F. (2020). Persistent Symptoms in Patients after Acute COVID-19. Jama 324, 603-605. doi:10.1001/jama.2020.12603

Caro-Codón, J., Rey, J. R., Buño, A., Iniesta, A. M., Rosillo, S. O., CastrejonCastrejon, S., et al. (2021). Characterization of Myocardial Injury in a Cohort of Patients with SARS-CoV-2 Infection. Med. Clin. (Barc) 157, 274-280. doi:10. 1016/j.medcli.2021.02.001

Carsana, L., Sonzogni, A., Nasr, A., Rossi, R. S., Pellegrinelli, A., Zerbi, P., et al. (2020). Pulmonary post-mortem Findings in a Series of COVID-19 Cases from Northern Italy: a Two-centre Descriptive Study. Lancet Infect. Dis. 20, 1135-1140. doi:10.1016/s1473-3099(20)30434-5

Carubbi, F., Salvati, L., Alunno, A., Maggi, F., Borghi, E., Mariani, R., et al. (2021). Ferritin Is Associated with the Severity of Lung Involvement but Not with Worse Prognosis in Patients with COVID-19: Data from Two Italian COVID19 Units. Sci. Rep. 11, 4863. doi:10.1038/s41598-021-83831-8

Carvalho-Schneider, C., Laurent, E., Lemaignen, A., Beaufils, E., BourbaoTournois, C., Laribi, S., et al. (2021). Follow-up of Adults with Noncritical COVID-19 Two Months after Symptom Onset. Clin. Microbiol. Infect. 27, 258-263. doi:10.1016/j.cmi.2020.09.052

Chan, S.-P., Kao, D.-I., Tsai, W.-Y., and Cheng, S.-C. (2003). The Prp19pAssociated Complex in Spliceosome Activation. Science 302, 279-282. doi:10.1126/science.1086602

Chen, H., Liu, W., Wang, Y., Liu, D., Zhao, L., and Yu, J. (2021). SARS-CoV-2 Activates Lung Epithelial Cell Proinflammatory Signaling and Leads to Immune Dysregulation in COVID-19 Patients. EBioMedicine 70, 103500. doi:10.1016/j.ebiom.2021.103500

Chen, L., Li, X., Chen, M., Feng, Y., and Xiong, C. (2020). The ACE2 Expression in Human Heart Indicates New Potential Mechanism of Heart Injury Among Patients Infected with SARS-CoV-2. Cardiovasc. Res. 116, 1097-1100. doi:10. 1093/cvr/cvaa078

Cheng, Y., Luo, R., Wang, K., Zhang, M., Wang, Z., Dong, L., et al. (2020). Kidney Disease Is Associated with In-Hospital Death of Patients with COVID-19. Kidney Int. 97, 829-838. doi:10.1016/j.kint.2020.03.005

Chioh, F. W., Fong, S. W., Young, B. E., Wu, K. X., Siau, A., Krishnan, S., et al. (2021). Convalescent COVID-19 Patients Are Susceptible to Endothelial Dysfunction Due to Persistent Immune Activation. Elife 10, e64909. doi:10. 7554/eLife.64909

Chobufo, M. D., Gayam, V., Soluny, J., Rahman, E. U., Enoru, S., Foryoung, J. B., et al. (2020). Prevalence and Control Rates of Hypertension in the USA: 20172018. Int. J. Cardiol. Hypertens. 6, 100044. doi:10.1016/j.ijchy.2020.100044

Chung, M., Zidar, D., Bristow, M., Cameron, S., Chan, T., Harding, C., et al. (2021). COVID-19 and Cardiovascular Disease: From Bench to Bedside. Circ. Res. 128 (8), 1214-1236. doi:10.1161/CIRCRESAHA.121.317997

Coate, K. C., Cha, J., Shrestha, S., Wang, W., Gonçalves, L. M., Almaça, J., et al. (2020). SARS-CoV-2 Cell Entry Factors ACE2 and TMPRSS2 Are Expressed in the Microvasculature and Ducts of Human Pancreas but Are Not Enriched in $\beta$ Cells. Cel Metab. 32, 1028-1040. e1024. doi:10.1016/j.cmet.2020.11.006

Cocozza, F., Névo, N., Piovesana, E., Lahaye, X., Buchrieser, J., Schwartz, O., et al. (2020). Extracellular Vesicles Containing ACE2 Efficiently Prevent Infection by SARS-CoV-2 Spike Protein-Containing Virus. J. Extracell Vesicles 10, e12050. doi:10.1002/jev2.12050

Constant, O., Barthelemy, J., Bolloré, K., Tuaillon, E., Gosselet, F., Chable-Bessia, C., et al. (2021). SARS-CoV-2 Poorly Replicates in Cells of the Human BloodBrain Barrier without Associated Deleterious Effects. Front. Immunol. 12, 697329. doi:10.3389/fimmu.2021.697329

Coromilas, E. J., Kochav, S., Goldenthal, I., Biviano, A., Garan, H., Goldbarg, S., et al. (2021). Worldwide Survey of COVID-19-Associated Arrhythmias. Circ. Arrhythm Electrophysiol. 14, e009458. doi:10.1161/CIRCEP.120.009458

Cotter, A. H., Yang, S. T., Shafi, H., Cotter, T. M., and Palmer-Toy, D. E. (2021). Elevated von Willebrand Factor Antigen is an Early Predictor of Mortality and Prolonged Length of Stay for Coronavirus Disease 2019 (COVID-19) Inpatients. Arch. Pathol. Lab. Med. 146 (1), 34-37. doi:10.5858/arpa.20210255-sa
Courand, P.-Y., Harbaoui, B., Bonnet, M., and Lantelme, P. (2020). Spontaneous Coronary Artery Dissection in a Patient with COVID-19. JACC: Cardiovasc. Interventions 13, e107-e108. doi:10.1016/j.jcin.2020.04.006

Crackower, M. A., Sarao, R., Oudit, G. Y., Yagil, C., Kozieradzki, I., Scanga, S. E., et al. (2002). Angiotensin-converting Enzyme 2 Is an Essential Regulator of Heart Function. Nature 417, 822-828. doi:10.1038/nature00786

Cugno, M., Meroni, P. L., Gualtierotti, R., Griffini, S., Grovetti, E., Torri, A., et al. (2020). Complement Activation in Patients with COVID-19: A Novel Therapeutic Target. J. Allergy Clin. Immunol. 146, 215-217. doi:10.1016/j. jaci.2020.05.006

Cummings, M. J., Baldwin, M. R., Abrams, D., Jacobson, S. D., Meyer, B. J., Balough, E. M., et al. (2020). Epidemiology, Clinical Course, and Outcomes of Critically Ill Adults with COVID-19 in New York City: a Prospective Cohort Study. The Lancet 395, 1763-1770. doi:10.1016/s0140-6736(20) 31189-2

D'agnillo, F., Walters, K. A., Xiao, Y., Sheng, Z. M., Scherler, K., Park, J., et al. (2021). Lung Epithelial and Endothelial Damage, Loss of Tissue Repair, Inhibition of Fibrinolysis, and Cellular Senescence in Fatal COVID-19. Sci. Transl Med. 13 (620), eabj7790. doi:10.1126/scitranslmed.abj7790

Daniels, C. J., Rajpal, S., Greenshields, J. T., Rosenthal, G. L., Chung, E. H., Terrin, M., et al. (2021). Prevalence of Clinical and Subclinical Myocarditis in Competitive Athletes with Recent SARS-CoV-2 Infection. JAMA Cardiol. 6, 1078-1087. doi:10.1001/jamacardio.2021.2065

Das, D., and Podder, S. (2021). Unraveling the Molecular Crosstalk between Atherosclerosis and COVID-19 Comorbidity. Comput. Biol. Med. 134, 104459. doi:10.1016/j.compbiomed.2021.104459

De Marco Verissimo, C., O’brien, C., López Corrales, J., Dorey, A., Cwiklinski, K., Lalor, R., et al. (2021). Improved Diagnosis of SARS-CoV-2 by Using Nucleoprotein and Spike Protein Fragment 2 in Quantitative Dual ELISA Tests. Epidemiol. Infect. 149, e140. doi:10.1017/s0950268821001308

de Vries, E., Tscherne, D. M., Wienholts, M. J., Cobos-Jiménez, V., Scholte, F., García-Sastre, A., et al. (2011). Dissection of the Influenza A Virus Endocytic Routes Reveals Macropinocytosis as an Alternative Entry Pathway. PLoS Pathog. 7 (3), e1001329. doi:10.1371/journal.ppat.1001329

Deinhardt-Emmer, S., Böttcher, S., Häring, C., Giebeler, L., Henke, A., Zell, R., et al. (2021). SARS-CoV-2 Causes Severe Epithelial Inflammation and Barrier Dysfunction. J. Virol. 95, e00110-21. doi:10.1128/jvi.00110-21

Del Valle, D. M., Kim-Schulze, S., Huang, H.-H., Beckmann, N. D., Nirenberg, S., Wang, B., et al. (2020). An Inflammatory Cytokine Signature Predicts COVID19 Severity and Survival. Nat. Med. 26, 1636-1643. doi:10.1038/s41591-020$1051-9$

Delrue, M., Siguret, V., Neuwirth, M., Joly, B., Beranger, N., Sène, D., et al. (2021). von Willebrand factor/ADAMTS13 axis and venous thromboembolism in moderate-to-severe COVID-19 patients. Br. J. Haematol. 192, 1097-1100. doi: $10.1111 /$ bjh. 17216

Dennison, D., Al Khabori, M., Al Mamari, S., Aurelio, A., Al Hinai, H., Al Maamari, K., et al. (2021). Circulating Activated Neutrophils in COVID-19: An Independent Predictor for Mechanical Ventilation and Death. Int. J. Infect. Dis. 106, 155-159. doi:10.1016/j.ijid.2021.03.066

Dillinger, J. G., Benmessaoud, F. A., Pezel, T., Voicu, S., Sideris, G., Chergui, N., et al. (2020). Coronary Artery Calcification and Complications in Patients with COVID-19. JACC: Cardiovasc. Imaging 13, 2468-2470. doi:10.1016/j.jcmg. 2020.07.004

Do, M. H., Stewart, C. R., and Harp, J. (2021). Cutaneous Manifestations of COVID-19 in the Inpatient Setting. Dermatol. Clin. 39, 521-532. doi:10.1016/j. det.2021.05.011

Donoghue, M., Hsieh, F., Baronas, E., Godbout, K., Gosselin, M., Stagliano, N., et al. (2000). A Novel Angiotensin-Converting Enzyme-Related Carboxypeptidase (ACE2) Converts Angiotensin I to Angiotensin 1-9. Circ. Res. 87, E1-E9. doi:10. 1161/01.res.87.5.e1

Drosten, C., Günther, S., Preiser, W., Van Der Werf, S., Brodt, H.-R., Becker, S., et al. (2003). Identification of a Novel Coronavirus in Patients with Severe Acute Respiratory Syndrome. N. Engl. J. Med. 348, 1967-1976. doi:10.1056/ nejmoa030747

Dweck, M. R., Bularga, A., Hahn, R. T., Bing, R., Lee, K. K., Chapman, A. R., et al. (2020). Global Evaluation of Echocardiography in Patients with COVID-19. Eur. Heart J. - Cardiovasc. Imaging 21, 1. doi:10.1093/ehjci/jeaa178 
Ellul, M. A., Benjamin, L., Singh, B., Lant, S., Michael, B. D., Easton, A., et al. (2020). Neurological Associations of COVID-19. Lancet Neurol. 19, 767-783. doi:10. 1016/s1474-4422(20)30221-0

Falasca, L., Nardacci, R., Colombo, D., Lalle, E., Di Caro, A., Nicastri, E., et al. (2020). Postmortem Findings in Italian Patients with COVID-19: A Descriptive Full Autopsy Study of Cases with and without Comorbidities. J. Infect. Dis. 222, 1807-1815. doi:10.1093/infdis/jiaa578

Fang, L., Karakiulakis, G., and Roth, M. (2020). Are Patients with Hypertension and Diabetes Mellitus at Increased Risk for COVID-19 Infection? Lancet Respir. Med. 8, e21. doi:10.1016/s2213-2600(20)30116-8

Favaloro, E. J., Henry, B. M., and Lippi, G. (2021). Increased VWF and Decreased ADAMTS-13 in COVID-19: Creating a Milieu for (Micro)Thrombosis. Semin. Thromb. Hemost. 47, 400-418. doi:10.1055/s-0041-1727282

Fernández-Martínez, N. F., Ortiz-González-Serna, R., Serrano-Ortiz, Á., RiveraIzquierdo, M., Ruiz-Montero, R., Pérez-Contreras, M., et al. (2021). Sex Differences and Predictors of In-Hospital Mortality Among Patients with COVID-19: Results from the ANCOHVID Multicentre Study. Int. J. Environ. Res. Public Health 18, 9018. doi:10.3390/ijerph18179018

Flude, B. M., Nannetti, G., Mitchell, P., Compton, N., Richards, C., Heurich, M., et al. (2021). Targeting the Complement Serine Protease MASP-2 as a Therapeutic Strategy for Coronavirus Infections. Viruses 13, 312. doi:10. 3390/v13020312

Fogarty, H., Townsend, L., Morrin, H., Ahmad, A., Comerford, C., Karampini, E., et al. (2021). Persistent Endotheliopathy in the Pathogenesis of Long COVID Syndrome. J. Thromb. Haemost. 19, 2546-2553. doi:10.1111/jth.15490

Fox, S. E., Akmatbekov, A., Harbert, J. L., Li, G., Quincy Brown, J., and Vander Heide, R. S. (2020). Pulmonary and Cardiac Pathology in African American Patients with COVID-19: an Autopsy Series from New Orleans. Lancet Respir. Med. 8, 681-686. doi:10.1016/s2213-2600(20)30243-5

Fraser, D. D., Patterson, E. K., Slessarev, M., Gill, S. E., Martin, C., Daley, M., et al. (2020). Endothelial Injury and Glycocalyx Degradation in Critically Ill Coronavirus Disease 2019 Patients: Implications for Microvascular Platelet Aggregation. Crit. Care Explor 2, e0194. doi:10.1097/cce.0000000000000194

Fuchs, V., Kutza, M., Wischnewski, S., Deigendesch, N., Lutz, L., Kulsvehagen, L., et al. (2021). Presence of SARS-CoV-2 Transcripts in the Choroid Plexus of MS and Non-MS Patients with COVID-19. Neurol. Neuroimmunol Neuroinflamm 8, e957. doi:10.1212/NXI.0000000000000957

Gao, Y. d., Ding, M., Dong, X., Zhang, J. j., Kursat Azkur, A., Azkur, D., et al. (2021). Risk Factors for Severe and Critically Ill COVID-19 Patients: A Review. Allergy 76, 428-455. doi:10.1111/all.14657

Garnier-Crussard, A., Forestier, E., Gilbert, T., and Krolak-Salmon, P. (2020). Novel Coronavirus (COVID-19) Epidemic: What Are the Risks for Older Patients? J. Am. Geriatr. Soc. 68, 939-940. doi:10.1111/jgs.16407

Giustino, G., Croft, L. B., Stefanini, G. G., Bragato, R., Silbiger, J. J., Vicenzi, M., et al. (2020). Characterization of Myocardial Injury in Patients with COVID-19. J. Am. Coll. Cardiol. 76, 2043-2055. doi:10.1016/j.jacc.2020. 08.069

Glasgow, A., Glasgow, J., Limonta, D., Solomon, P., Lui, I., Zhang, Y., et al. (2020). Engineered ACE2 Receptor Traps Potently Neutralize SARS-CoV-2. Proc. Natl. Acad. Sci. USA 117, 28046-28055. doi:10.1073/pnas.2016093117

Goshua, G., Pine, A. B., Meizlish, M. L., Chang, C.-H., Zhang, H., Bahel, P., et al. (2020). Endotheliopathy in COVID-19-Associated Coagulopathy: Evidence from a single-centre, Cross-Sectional Study. Lancet Haematol. 7, e575-e582. doi:10.1016/s2352-3026(20)30216-7

Grasselli, G., Greco, M., Zanella, A., Albano, G., Antonelli, M., Bellani, G., et al. (2020). Risk Factors Associated with Mortality Among Patients with COVID19 in Intensive Care Units in Lombardy, Italy. JAMA Intern. Med. 180, 1345-1355. doi:10.1001/jamainternmed.2020.3539

Gratz, J., Wiegele, M., Maleczek, M., Herkner, H., Schöchl, H., Chwala, E., et al. (2021). Risk of Clinically Relevant Venous Thromboembolism in Critically Ill Patients with COVID-19: A Systematic Review and Meta-Analysis. Front. Med. 8, 647917. doi:10.3389/fmed.2021.647917

Groß, S., Jahn, C., Cushman, S., Bär, C., and Thum, T. (2020). SARS-CoV-2 Receptor ACE2-dependent Implications on the Cardiovascular System: From Basic Science to Clinical Implications. J. Mol. Cel Cardiol 144, 47-53. doi:10. 1016/j.yjmcc.2020.04.031

Gu, S. X., Tyagi, T., Jain, K., Gu, V. W., Lee, S. H., Hwa, J. M., et al. (2021). Thrombocytopathy and Endotheliopathy: Crucial Contributors to COVID-19
Thromboinflammation. Nat. Rev. Cardiol. 18, 194-209. doi:10.1038/s41569020-00469-1

Guervilly, C., Burtey, S., Sabatier, F., Cauchois, R., Lano, G., Abdili, E., et al. (2020). Circulating Endothelial Cells as a Marker of Endothelial Injury in Severe COVID -19. J. Infect. Dis. 222, 1789-1793. doi:10.1093/infdis/jiaa528

Guo, Y.-R., Cao, Q.-D., Hong, Z.-S., Tan, Y.-Y., Chen, S.-D., Jin, H.-J., et al. (2020). The Origin, Transmission and Clinical Therapies on Coronavirus Disease 2019 (COVID-19) Outbreak - an Update on the Status. Mil. Med Res. 7, 11. doi:10. 1186/s40779-020-00240-0

Hadi, A., Werge, M., Kristiansen, K. T., Pedersen, U. G., Karstensen, J. G., Novovic, S., et al. (2020). Coronavirus Disease-19 (COVID-19) Associated with Severe Acute Pancreatitis: Case Report on Three Family Members. Pancreatology 20, 665-667. doi:10.1016/j.pan.2020.04.021

Haiduc, A. A., Ogunjimi, M., Shammus, R., Mahmood, S., Kutty, R., Lotto, A., et al. (2021). COVID-19 and Congenital Heart Disease: an Insight of Pathophysiology and Associated Risks. Cardiol. Young 31, 233-240. doi:10. 1017/s1047951120003741

Halpin, S. J., Mcivor, C., Whyatt, G., Adams, A., Harvey, O., Mclean, L., et al. (2021). Postdischarge Symptoms and Rehabilitation Needs in Survivors of COVID-19 Infection: A Cross-sectional Evaluation. J. Med. Virol. 93, 1013-1022. doi:10.1002/jmv.26368

Hamming, I., Timens, W., Bulthuis, M., Lely, A., Navis, G., and Van Goor, H. (2004). Tissue Distribution of ACE2 Protein, the Functional Receptor for SARS Coronavirus. A First Step in Understanding SARS Pathogenesis. J. Pathol. 203, 631-637. doi:10.1002/path.1570

Hammoud, S. H., Wehbe, Z., Abdelhady, S., Kobeissy, F., Eid, A. H., and El-Yazbi, A. F. (2021). Dysregulation of Angiotensin Converting Enzyme 2 Expression and Function in Comorbid Disease Conditions Possibly Contributes to Coronavirus Infectious Disease 2019 Complication Severity. Mol. Pharmacol. 99, 17-28. doi:10.1124/molpharm.120.000119

He, L., Mäe, M. A., Muhl, L., Sun, Y., Pietilä, R., Nahar, K., et al. (2020). Pericytespecific Vascular Expression of SARS-CoV-2 Receptor ACE2 - Implications for Microvascular Inflammation and Hypercoagulopathy in COVID-19. bioRxiv 2020, 088500. doi:10.1101/2020.05.11.088500

Helms, J., Severac, F., Merdji, H., Anglés-Cano, E., and Meziani, F. (2020). Prothrombotic Phenotype in COVID-19 Severe Patients. Intensive Care Med. 46, 1502-1503. doi:10.1007/s00134-020-06082-7

Hikmet, F., Méar, L., Edvinsson, A., Micke, P., Uhlén, M., and Lindskog, C. (2020). The Protein Expression Profile of ACE2 in Human Tissues. Mol. Syst. Biol. 16, e9610. doi: $10.15252 / \mathrm{msb} .20209610$

Hoffmann, H.-H., Sánchez-Rivera, F. J., Schneider, W. M., Luna, J. M., SotoFeliciano, Y. M., Ashbrook, A. W., et al. (2021a). Functional Interrogation of a SARS-CoV-2 Host Protein Interactome Identifies Unique and Shared Coronavirus Host Factors. Cell Host \& Microbe 29, 267-280. e265. doi:10. 1016/j.chom.2020.12.009

Hoffmann, M., Kleine-Weber, H., Schroeder, S., Krüger, N., Herrler, T., Erichsen, S., et al. (2020). SARS-CoV-2 Cell Entry Depends on ACE2 and TMPRSS2 and Is Blocked by a Clinically Proven Protease Inhibitor. Cell 181, 271-280. doi:10. 1016/j.cell.2020.02.052

Hoffmann, M., Kruger, N., Schulz, S., Cossmann, A., Rocha, C., Kempf, A., et al. (2021b). The Omicron Variant Is Highly Resistant against Antibody-Mediated Neutralization: Implications for Control of the COVID-19 Pandemic. Cell 1, 1. doi:10.1016/j.cell.2021.12.032

Hogan, C. A., Stevens, B. A., Sahoo, M. K., Huang, C., Garamani, N., Gombar, S., et al. (2021). High Frequency of SARS-CoV-2 RNAemia and Association with Severe Disease. Clin. Infect. Dis. 72, e291-e295. doi:10.1093/cid/ ciaa 1054

Holm, A., Heumann, T., and Augustin, H. G. (2018). Microvascular Mural Cell Organotypic Heterogeneity and Functional Plasticity. Trends Cel Biol. 28, 302-316. doi:10.1016/j.tcb.2017.12.002

Holter, J. C., Pischke, S. E., De Boer, E., Lind, A., Jenum, S., Holten, A. R., et al. (2020). Systemic Complement Activation Is Associated with Respiratory Failure in COVID-19 Hospitalized Patients. Proc. Natl. Acad. Sci. USA 117, 25018-25025. doi:10.1073/pnas.2010540117

Hou, Y. J., Okuda, K., Edwards, C. E., Martinez, D. R., Asakura, T., Dinnon, K. H., 3rd, et al. (2020). SARS-CoV-2 Reverse Genetics Reveals a Variable Infection Gradient in the Respiratory Tract. Cell 182, 429-446. e414. doi:10.1016/j.cell. 2020.05.042 
Huang, C., Huang, L., Wang, Y., Li, X., Ren, L., Gu, X., et al. (2021). 6-month Consequences of COVID-19 in Patients Discharged from Hospital: a Cohort Study. The Lancet 397, 220-232. doi:10.1016/s0140-6736(20)32656-8

Huang, C., Wang, Y., Li, X., Ren, L., Zhao, J., Hu, Y., et al. (2020). Clinical Features of Patients Infected with 2019 Novel Coronavirus in Wuhan, China. The Lancet 395, 497-506. doi:10.1016/s0140-6736(20)30183-5

Humphrey, J. D., and Schwartz, M. A. (2021). Vascular Mechanobiology: Homeostasis, Adaptation, and Disease. Annu. Rev. Biomed. Eng. 23, 1-27. doi:10.1146/annurev-bioeng-092419-060810

Iba, T., Levy, J. H., Levi, M., Connors, J. M., and Thachil, J. (2020). Coagulopathy of Coronavirus Disease 2019. Crit. Care Med. 48, 1358-1364. doi:10.1097/ccm. 0000000000004458

Jacob, F., Pather, S. R., Huang, W.-K., Zhang, F., Wong, S. Z. H., Zhou, H., et al. (2020). Human Pluripotent Stem Cell-Derived Neural Cells and Brain Organoids Reveal SARS-CoV-2 Neurotropism Predominates in Choroid Plexus Epithelium. Cell Stem Cell 27, 937-950. doi:10.1016/j.stem.2020.09.016

Jacobs, J. L., Bain, W., Naqvi, A., Staines, B., Castanha, P. M. S., Yang, H., et al. (2021). SARS-CoV-2 Viremia Is Associated with COVID-19 Severity and Predicts Clinical Outcomes. Clin. Infect. Dis. 1, ciab686. doi:10.1093/cid/ ciab686

Jaimes, J. A., Millet, J. K., and Whittaker, G. R. (2020). Proteolytic Cleavage of the SARS-CoV-2 Spike Protein and the Role of the Novel S1/S2 Site. iScience 23, 101212. doi:10.1016/j.isci.2020.101212

Jiménez, D., García-Sanchez, A., Rali, P., Muriel, A., Bikdeli, B., Ruiz-Artacho, P., et al. (2021). Incidence of VTE and Bleeding Among Hospitalized Patients with Coronavirus Disease 2019: A Systematic Review and Meta-Analysis. Chest 159, 1182-1196. doi:10.1016/j.chest.2020.11.005

Jonsdottir, H. R., and Dijkman, R. (2016). Coronaviruses and the Human Airway: a Universal System for Virus-Host Interaction Studies. Virol. J. 13, 24. doi:10. 1186/s12985-016-0479-5

Joy, G., Artico, J., Kurdi, H., Seraphim, A., Lau, C., Thornton, G. D., et al. (2021). Prospective Case-Control Study of Cardiovascular Abnormalities 6 Months Following Mild COVID-19 in Healthcare Workers. JACC: Cardiovasc. Imaging 14, 2155-2166. doi:10.1016/j.jcmg.2021.04.011

Kadosh, B. S., Garshick, M. S., Gaztanaga, J., Moore, K. J., Newman, J. D., Pillinger, M., et al. (2020). COVID-19 and the Heart and Vasculature. Atvb 40, 2045-2053. doi:10.1161/atvbaha.120.314513

Kalucka, J., De Rooij, L. P. M. H., Goveia, J., Rohlenova, K., Dumas, S. J., Meta, E., et al. (2020). Single-Cell Transcriptome Atlas of Murine Endothelial Cells. Cell 180, 764e720-779. doi:10.1016/j.cell.2020.01.015

Kamrath, C., Mönkemöller, K., Biester, T., Rohrer, T. R., Warncke, K., Hammersen, J., et al. (2020). Ketoacidosis in Children and Adolescents with Newly Diagnosed Type 1 Diabetes during the COVID-19 Pandemic in Germany. Jama 324, 801-804. doi:10.1001/jama.2020.13445

Kaneko, N., Satta, S., Komuro, Y., Muthukrishnan, S. D., Kakarla, V., Guo, L., et al. (2021). Flow-Mediated Susceptibility and Molecular Response of Cerebral Endothelia to SARS-CoV-2 Infection. Stroke 52, 260-270. doi:10.1161/ strokeaha.120.032764

Khan, M., Yoo, S.-J., Clijsters, M., Backaert, W., Vanstapel, A., Speleman, K., et al. (2021). Visualizing in Deceased COVID-19 Patients How SARS-CoV-2 Attacks the Respiratory and Olfactory Mucosae but Spares the Olfactory Bulb. Cell 184, 5932-5949. doi:10.1016/j.cell.2021.10.027

Kirschenbaum, D., Imbach, L. L., Rushing, E. J., Frauenknecht, K. B. M., Gascho, D., Ineichen, B. V., et al. (2021). Intracerebral Endotheliitis and Microbleeds Are Neuropathological Features of COVID-19. Neuropathol. Appl Neurobio 47, 454-459. doi:10.1111/nan.12677

Klok, F. A., Kruip, M. J. H. A., Van Der Meer, N. J. M., Arbous, M. S., Gommers, D. A. M. P. J., Kant, K. M., et al. (2020). Incidence of Thrombotic Complications in Critically Ill ICU Patients with COVID-19. Thromb. Res. 191, 145-147. doi:10. 1016/j.thromres.2020.04.013

Knight, D. S., Kotecha, T., Razvi, Y., Chacko, L., Brown, J. T., Jeetley, P. S., et al. (2020). Covid-19. Circulation 142, 1120-1122. doi:10.1161/circulationaha.120. 049252

Kondo, R., Kawaguchi, N., Mcconnell, M. J., Sonzogni, A., Licini, L., Valle, C., et al. (2021). Pathological Characteristics of Liver Sinusoidal Thrombosis in COVID19 Patients: A Series of 43 Cases. Hepatol. Res. 51, 1000-1006. doi:10.1111/hepr. 13696
Korber, B., Fischer, W. M., Gnanakaran, S., Yoon, H., Theiler, J., Abfalterer, W., et al. (2020). Tracking Changes in SARS-CoV-2 Spike: Evidence that D614G Increases Infectivity of the COVID-19 Virus. Cell 182, 812-827. doi:10.1016/j. cell.2020.06.043

Kotecha, T., Knight, D. S., Razvi, Y., Kumar, K., Vimalesvaran, K., Thornton, G., et al. (2021). Patterns of Myocardial Injury in Recovered Troponin-Positive COVID-19 Patients Assessed by Cardiovascular Magnetic Resonance. Eur. Heart J. 42, 1866-1878. doi:10.1093/eurheartj/ehab075

Kuiken, T., Fouchier, R. A., Schutten, M., Rimmelzwaan, G. F., Van Amerongen, G., Van Riel, D., et al. (2003). Newly Discovered Coronavirus as the Primary Cause of Severe Acute Respiratory Syndrome. The Lancet 362, 263-270. doi:10. 1016/s0140-6736(03)13967-0

Kumar, V., Singh, J., Hasnain, S. E., and Sundar, D. (2021). Possible Link between Higher Transmissibility of Alpha, Kappa and Delta Variants of SARS-CoV-2 and Increased Structural Stability of its Spike Protein and hACE2 Affinity. Int. J. Mol. Sci. 22, 9131. doi:10.3390/ijms22179131

Kuriakose, J., Montezano, A. C., and Touyz, R. M. (2021). ACE2/Ang-(1-7)/Mas1 axis and the Vascular System: Vasoprotection to COVID-19-Associated Vascular Disease. Clin. Sci. (Lond) 135, 387-407. doi:10.1042/cs20200480

Lagana, S. M., Kudose, S., Iuga, A. C., Lee, M. J., Fazlollahi, L., Remotti, H. E., et al. (2020). Hepatic Pathology in Patients Dying of COVID-19: a Series of 40 Cases Including Clinical, Histologic, and Virologic Data. Mod. Pathol. 33, 2147-2155. doi:10.1038/s41379-020-00649-x

Lampsas, S., Tsaplaris, P., Pantelidis, P., Oikonomou, E., Marinos, G., Charalambous, G., et al. (2021). The Role of Endothelial Related Circulating Biomarkers in COVID-19. A Systematic Review and Meta-Analysis. Curr. Med. Chem. 1, 1. doi:10.2174/0929867328666211026124033

Lax, S. F., Skok, K., Zechner, P., Kessler, H. H., Kaufmann, N., Koelblinger, C., et al. (2020). Pulmonary Arterial Thrombosis in COVID-19 with Fatal Outcome. Ann. Intern. Med. 173, 350-361. doi:10.7326/m20-2566

Lee, M.-H., Perl, D. P., Nair, G., Li, W., Maric, D., Murray, H., et al. (2021). Microvascular Injury in the Brains of Patients with Covid-19. N. Engl. J. Med. 384, 481-483. doi:10.1056/nejmc2033369

Lewis, A., Frontera, J., Placantonakis, D. G., Lighter, J., Galetta, S., Balcer, L., et al. (2021). Cerebrospinal Fluid in COVID-19: A Systematic Review of the Literature. J. Neurol. Sci. 421, 117316. doi:10.1016/j.jns.2021.117316

Lewis, M. J., Anderson, B. R., Fremed, M., Argenio, M., Krishnan, U., Weller, R., et al. (2020). Impact of Coronavirus Disease 2019 (COVID-19) on Patients with Congenital Heart Disease across the Lifespan: The Experience of an Academic Congenital Heart Disease Center in New York City. J. Am. Heart Assoc. 9, e017580. doi:10.1161/JAHA.120.017580

Li, J., Wang, X., Chen, J., Zuo, X., Zhang, H., and Deng, A. (2020). COVID -19 Infection May Cause Ketosis and Ketoacidosis. Diabetes Obes. Metab. 22, 1935-1941. doi:10.1111/dom.14057

Li, M., Lou, F., and Fan, H. (2021a). SARS-CoV-2 Variants of Concern Delta: a Great challenge to Prevention and Control of COVID-19. Sig Transduct Target. Ther. 6, 349. doi:10.1038/s41392-021-00767-1

Li, Y., Schneider, A. M., Mehta, A., Sade-Feldman, M., Kays, K. R., Gentili, M., et al. (2021b). SARS-CoV-2 Viremia Is Associated with Distinct Proteomic Pathways and Predicts COVID-19 Outcomes. J. Clin. Invest. 131, e148635. doi:10.1172/ jci148635

Litviňuková, M., Talavera-López, C., Maatz, H., Reichart, D., Worth, C. L., Lindberg, E. L., et al. (2020). Cells of the Adult Human Heart. Nature 588, 466-472. doi:10.1038/s41586-020-2797-4

Liu, Z., Vanblargan, L. A., Bloyet, L.-M., Rothlauf, P. W., Chen, R. E., Stumpf, S., et al. (2021). Identification of SARS-CoV-2 Spike Mutations that Attenuate Monoclonal and Serum Antibody Neutralization. Cell Host \& Microbe 29, 477-488. doi:10.1016/j.chom.2021.01.014

Long, B., Brady, W. J., Koyfman, A., and Gottlieb, M. (2020). Cardiovascular Complications in COVID-19. Am. J. Emerg. Med. 38, 1504-1507. doi:10.1016/j. ajem.2020.04.048

Lopez-Leon, S., Wegman-Ostrosky, T., Perelman, C., Sepulveda, R., Rebolledo, P. A., Cuapio, A., et al. (2021). More Than 50 Long-Term Effects of COVID-19: a Systematic Review and Meta-Analysis. Sci. Rep. 11, 16144. doi:10.1038/s41598021-95565-8

Lopez-Mendez, I., Aquino-Matus, J., Gall, S. M.-B., Prieto-Nava, J. D., JuarezHernandez, E., Uribe, M., et al. (2021). Association of Liver Steatosis and 
Fibrosis with Clinical Outcomes in Patients with SARS-CoV-2 Infection (COVID-19). Ann. Hepatol. 20, 100271. doi:10.1016/j.aohep.2020.09.015

Lu, R., Zhao, X., Li, J., Niu, P., Yang, B., Wu, H., et al. (2020). Genomic Characterisation and Epidemiology of 2019 Novel Coronavirus: Implications for Virus Origins and Receptor Binding. The Lancet 395, 565-574. doi:10.1016/ s0140-6736(20)30251-8

Lu, S., Ye, Q., Singh, D., Cao, Y., Diedrich, J. K., Yates, J. R., 3rd, et al. (2021). The SARS-CoV-2 Nucleocapsid Phosphoprotein Forms Mutually Exclusive Condensates with RNA and the Membrane-Associated M Protein. Nat. Commun. 12, 502. doi:10.1038/s41467-020-20768-y

Lukassen, S., Chua, R. L., Trefzer, T., Kahn, N. C., Schneider, M. A., Muley, T., et al. (2020). SARS-CoV-2 Receptor ACE2 and TMPRSS2 Are Primarily Expressed in Bronchial Transient Secretory Cells. Embo j 39, e105114. doi:10.15252/embj. 2020105114

Ma, L., Sahu, S. K., Cano, M., Kuppuswamy, V., Bajwa, J., Mcphatter, J., et al. (2021a). Increased Complement Activation Is a Distinctive Feature of Severe SARS-CoV-2 Infection. Sci. Immunol. 6, eabh2259. doi:10.1126/sciimmunol. abh2259

Ma, X., Guan, C., Chen, R., Wang, Y., Feng, S., Wang, R., et al. (2021b). Pathological and Molecular Examinations of Postmortem Testis Biopsies Reveal SARS-CoV2 Infection in the Testis and Spermatogenesis Damage in COVID-19 Patients. Cell Mol Immunol 18, 487-489. doi:10.1038/s41423-020-00604-5

Maccio, U., Zinkernagel, A. S., Shambat, S. M., Zeng, X., Cathomas, G., Ruschitzka, F., et al. (2021). SARS-CoV-2 Leads to a Small Vessel Endotheliitis in the Heart. EBioMedicine 63, 103182. doi:10.1016/j.ebiom.2020.103182

Macor, P., Durigutto, P., Mangogna, A., Bussani, R., DeMaso, L., D’Errico, S., et al. (2021). Multiple-Organ Complement Deposition on Vascular Endothelium in COVID-19 Patients. Biomedicines. 9 (8), 1003. doi:10.3390/ biomedicines 9081003

Madjid, M., Safavi-Naeini, P., Solomon, S. D., and Vardeny, O. (2020). Potential Effects of Coronaviruses on the Cardiovascular System. JAMA Cardiol. 5, 831-840. doi:10.1001/jamacardio.2020.1286

Magro, C., Mulvey, J. J., Berlin, D., Nuovo, G., Salvatore, S., Harp, J., et al. (2020). Complement Associated Microvascular Injury and Thrombosis in the Pathogenesis of Severe COVID-19 Infection: A Report of Five Cases. Translational Res. 220, 1-13. doi:10.1016/j.trsl.2020.04.007

Mancini, I., Baronciani, L., Artoni, A., Colpani, P., Biganzoli, M., Cozzi, G., et al. (2021). The ADAMTS13-von Willebrand Factor axis in COVID-19 Patients. J. Thromb. Haemost. 19, 513-521. doi:10.1111/jth.15191

Manne, B. K., Denorme, F., Middleton, E. A., Portier, I., Rowley, J. W., Stubben, C., et al. (2020). Platelet Gene Expression and Function in Patients with COVID19. Blood 136, 1317-1329. doi:10.1182/blood.2020007214

Manocha, K. K., Kirzner, J., Ying, X., Yeo, I., Peltzer, B., Ang, B., et al. (2021). Troponin and Other Biomarker Levels and Outcomes Among Patients Hospitalized with COVID-19: Derivation and Validation of the HA2T2 COVID-19 Mortality Risk Score. J. Am. Heart Assoc. 10, e018477. doi:10.1161/JAHA.120.018477

Marchiano, S., Hsiang, T.-Y., Khanna, A., Higashi, T., Whitmore, L. S., Bargehr, J., et al. (2021). SARS-CoV-2 Infects Human Pluripotent Stem Cell-Derived Cardiomyocytes, Impairing Electrical and Mechanical Function. Stem Cel Rep. 16, 478-492. doi:10.1016/j.stemcr.2021.02.008

Maruhashi, T., and Higashi, Y. (2021). Pathophysiological Association of Endothelial Dysfunction with Fatal Outcome in COVID-19. Int. J. Mol. Sci. 22, 5131. doi:10.3390/ijms22105131

Massoth, L. R., Desai, N., Szabolcs, A., Harris, C. K., Neyaz, A., Crotty, R., et al. (2021). Comparison of RNA In Situ Hybridization and Immunohistochemistry Techniques for the Detection and Localization of SARS-CoV-2 in Human Tissues. Am. J. Surg. Pathol. 45, 14-24. doi:10.1097/pas.0000000000001563

Matschke, J., Lütgehetmann, M., Hagel, C., Sperhake, J. P., Schröder, A. S., Edler, C., et al. (2020). Neuropathology of Patients with COVID-19 in Germany: a post-mortem Case Series. Lancet Neurol. 19, 919-929. doi:10.1016/s14744422(20)30308-2

Mccracken, I. R., Saginc, G., He, L., Huseynov, A., Daniels, A., Fletcher, S., et al. (2021). Lack of Evidence of Angiotensin-Converting Enzyme 2 Expression and Replicative Infection by SARS-CoV-2 in Human Endothelial Cells. Circulation 143, 865-868. doi:10.1161/circulationaha.120.052824
Mcfadden, E. R., Jr., Pichurko, B. M., Bowman, H. F., Ingenito, E., Burns, S., Dowling, N., et al. (19851985). Thermal Mapping of the Airways in Humans. J. Appl. Physiol. 58, 564-570. doi:10.1152/jappl.1985.58.2.564

Medeiros, A. K., Barbisan, C. C., Cruz, I. R., de Araújo, E. M., Libânio, B. B., Albuquerque, K. S., et al. (2020). Higher Frequency of Hepatic Steatosis at CT Among COVID-19-Positive Patients. Abdom. Radiol. 45, 2748-2754. doi:10. 1007/s00261-020-02648-7

Mehta, P., Mcauley, D. F., Brown, M., Sanchez, E., Tattersall, R. S., and Manson, J. J. (2020). Hlh across Speciality Collaboration, U.KCOVID-19: Consider Cytokine Storm Syndromes and Immunosuppression. The Lancet 395, 1033-1034. doi:10.1016/s0140-6736(20)30628-0

Mei, Y., Weinberg, S. E., Zhao, L., Frink, A., Qi, C., Behdad, A., et al. (2020). Risk Stratification of Hospitalized COVID-19 Patients through Comparative Studies of Laboratory Results with Influenza. EClinicalMedicine 26, 100475. doi:10. 1016/j.eclinm.2020.100475

Meinhardt, J., Radke, J., Dittmayer, C., Franz, J., Thomas, C., Mothes, R., et al. (2021). Olfactory Transmucosal SARS-CoV-2 Invasion as a Port of central Nervous System Entry in Individuals with COVID-19. Nat. Neurosci. 24, 168-175. doi:10.1038/s41593-020-00758-5

Meng, J., Xiao, G., Zhang, J., He, X., Ou, M., Bi, J., et al. (2020). Renin-angiotensin System Inhibitors Improve the Clinical Outcomes of COVID-19 Patients with Hypertension. Emerging Microbes \& Infections 9, 757-760. doi:10.1080/ 22221751.2020.1746200

Menter, T., Haslbauer, J. D., Nienhold, R., Savic, S., Hopfer, H., Deigendesch, N., et al. (2020). Postmortem Examination of COVID-19 Patients Reveals Diffuse Alveolar Damage with Severe Capillary Congestion and Variegated Findings in Lungs and Other Organs Suggesting Vascular Dysfunction. Histopathology 77, 198-209. doi:10.1111/his.14134

Merle, N. S., Church, S. E., Fremeaux-Bacchi, V., and Roumenina, L. T. (2015). Complement System Part I Â€" Molecular Mechanisms of Activation and Regulation. Front. Immunol. 6, 262. doi:10.3389/fimmu.2015.00262

Middleton, E. A., He, X.-Y., Denorme, F., Campbell, R. A., Ng, D., Salvatore, S. P., et al. (2020). Neutrophil Extracellular Traps Contribute to Immunothrombosis in COVID-19 Acute Respiratory Distress Syndrome. Blood 136, 1169-1179. doi:10.1182/blood.2020007008

Montefusco, L., Ben Nasr, M., D’Addio, F., Loretelli, C., Rossi, A., Pastore, I., et al. (2021). Acute and Long-Term Disruption of Glycometabolic Control after SARS-CoV-2 Infection. Nat. Metab. 3, 774-785. doi:10.1038/s42255-02100407-6

Monteil, V., Kwon, H., Prado, P., Hagelkrüys, A., Wimmer, R. A., Stahl, M., et al. (2020). Inhibition of SARS-CoV-2 Infections in Engineered Human Tissues Using Clinical-Grade Soluble Human ACE2. Cell 181, 905-913. e907. doi:10. 1016/j.cell.2020.04.004

Müller, J. A., Groß, R., Conzelmann, C., Krüger, J., Merle, U., Steinhart, J., et al. (2021). SARS-CoV-2 Infects and Replicates in Cells of the Human Endocrine and Exocrine Pancreas. Nat. Metab. 3, 149-165. doi:10.1038/s42255-02100347-1

Muus, C., Luecken, M. D., Luecken, M. D., Eraslan, G., Sikkema, L., Waghray, A., et al. (2021). Single-cell Meta-Analysis of SARS-CoV-2 Entry Genes across Tissues and Demographics. Nat. Med. 27, 546-559. doi:10.1038/s41591-020$01227-\mathrm{z}$

Nalbandian, A., Sehgal, K., Gupta, A., Madhavan, M. V., Mcgroder, C., Stevens, J. S., et al. (2021). Post-acute COVID-19 Syndrome. Nat. Med. 27, 601-615. doi:10.1038/s41591-021-01283-z

Nandadeva, D., Young, B. E., Stephens, B. Y., Grotle, A.-K., Skow, R. J., Middleton, A. J., et al. (2021). Blunted Peripheral but Not Cerebral Vasodilator Function in Young Otherwise Healthy Adults with Persistent Symptoms Following COVID-19. Am. J. Physiology-Heart Circulatory Physiol. 321, H479-H484. doi:10.1152/ajpheart.00368.2021

Nascimento Conde, J., Schutt, W. R., Gorbunova, E. E., and Mackow, E. R. (2020). Recombinant ACE2 Expression Is Required for SARS-CoV-2 to Infect Primary Human Endothelial Cells and Induce Inflammatory and Procoagulative Responses. mBio 11, e03185-20. doi:10.1128/mBio.03185-20

Neubauer, K., and Zieger, B. (2021). Endothelial Cells and Coagulation. Cell Tissue Res. 1, 1. doi:10.1007/s00441-021-03471-2

Nicin, L., Abplanalp, W. T., Mellentin, H., Kattih, B., Tombor, L., John, D., et al. (2020). Cell Type-specific Expression of the Putative SARS-CoV-2 Receptor 
ACE2 in Human Hearts. Eur. Heart J. 41, 1804-1806. doi:10.1093/eurheartj/ ehaa311

Nicolai, L., Leunig, A., Brambs, S., Kaiser, R., Weinberger, T., Weigand, M., et al. (2020). Immunothrombotic Dysregulation in COVID-19 Pneumonia Is Associated with Respiratory Failure and Coagulopathy. Circulation 142, 1176-1189. doi:10.1161/circulationaha.120.048488

Nicosia, R. F., Ligresti, G., Caporarello, N., Akilesh, S., and Ribatti, D. (2021). COVID-19 Vasculopathy: Mounting Evidence for an Indirect Mechanism of Endothelial Injury. Am. J. Pathol. 191, 1374-1384. doi:10.1016/j.ajpath.2021. 05.007

Norooznezhad, A. H., and Mansouri, K. (2021). Endothelial Cell Dysfunction, Coagulation, and Angiogenesis in Coronavirus Disease 2019 (COVID-19). Microvasc. Res. 137, 104188. doi:10.1016/j.mvr.2021.104188

Nuovo, G. J., Magro, C., Shaffer, T., Awad, H., Suster, D., Mikhail, S., et al. (2021). Endothelial Cell Damage Is the central Part of COVID-19 and a Mouse Model Induced by Injection of the S1 Subunit of the Spike Protein. Ann. Diagn. Pathol. 51, 151682. doi:10.1016/j.anndiagpath.2020.151682

O'connell, T. F., Bradley, C. J., Abbas, A. E., Williamson, B. D., Rusia, A., Tawney, A. M., et al. (2021). Hydroxychloroquine/Azithromycin Therapy and QT Prolongation in Hospitalized Patients with COVID-19. JACC Clin. Electrophysiol. 7, 16-25. doi:10.1016/j.jacep.2020.07.016

Oliva, A., Rando, E., Al Ismail, D., De Angelis, M., Cancelli, F., Miele, M. C., et al. (2021). Role of Serum E-Selectin as a Biomarker of Infection Severity in Coronavirus Disease 2019. J. Clin. Med. 10, 1. doi:10.3390/jcm10174018

Onder, G., Rezza, G., and Brusaferro, S. (2020). Case-Fatality Rate and Characteristics of Patients Dying in Relation to COVID-19 in Italy. Jama 323, 1775-1776. doi:10.1001/jama.2020.4683

Oran, D. P., and Topol, E. J. (2020). Prevalence of Asymptomatic SARS-CoV-2 Infection. Ann. Intern. Med. 173, 362-367. doi:10.7326/m20-3012

Paik, D. T., Tian, L., Williams, I. M., Rhee, S., Zhang, H., Liu, C., et al. (2020). Single-Cell RNA Sequencing Unveils Unique Transcriptomic Signatures of Organ-specific Endothelial Cells. Circulation 142, 1848-1862. doi:10.1161/ circulationaha.119.041433

Pajo, A. T., Espiritu, A. I., Apor, A. D. A. O., and Jamora, R. D. G. (2021). Neuropathologic Findings of Patients with COVID-19: a Systematic Review. Neurol. Sci. 42, 1255-1266. doi:10.1007/s10072-021-05068-7

Pan, C., Zhang, Z., Luo, L., Wu, W., Jia, T., Lu, L., et al. (2021). Cardiac T1 and T2 Mapping Showed Myocardial Involvement in Recovered COVID -19 Patients Initially Considered Devoid of Cardiac Damage. J. Magn. Reson. Imaging 54, 421-428. doi:10.1002/jmri.27534

Pandanaboyana, S., Moir, J., Leeds, J. S., Oppong, K., Kanwar, A., Marzouk, A., et al. (2021). SARS-CoV-2 Infection in Acute Pancreatitis Increases Disease Severity and 30-day Mortality: COVID PAN Collaborative Study. Gut 70, 1061-1069. doi:10.1136/gutjnl-2020-323364

Papa, G., Mallery, D. L., Albecka, A., Welch, L. G., Cattin-Ortolá, J., Luptak, J., et al. (2021). Furin Cleavage of SARS-CoV-2 Spike Promotes but Is Not Essential for Infection and Cell-Cell Fusion. Plos Pathog. 17, e1009246. doi:10.1371/journal. ppat.1009246

Parasa, S., Desai, M., Thoguluva Chandrasekar, V., Patel, H. K., Kennedy, K. F., Roesch, T., et al. (2020). Prevalence of Gastrointestinal Symptoms and Fecal Viral Shedding in Patients with Coronavirus Disease 2019. JAMA Netw. Open 3, e2011335. doi:10.1001/jamanetworkopen.2020.11335

Parra-Medina, R., Herrera, S., and Mejia, J. (2021). Systematic Review of Microthrombi in COVID-19 Autopsies. Acta Haematol. 144, 476-483. doi:10.1159/000515104

Paul, M., Poyan Mehr, A., and Kreutz, R. (2006). Physiology of Local ReninAngiotensin Systems. Physiol. Rev. 86, 747-803. doi:10.1152/physrev.00036. 2005

Pellegrini, D., Kawakami, R., Guagliumi, G., Sakamoto, A., Kawai, K., Gianatti, A., et al. (2021). Microthrombi as a Major Cause of Cardiac Injury in COVID-19. Circulation 143, 1031-1042. doi:10.1161/circulationaha.120.051828

Pellegrini, L., Albecka, A., Mallery, D. L., Kellner, M. J., Paul, D., Carter, A. P., et al. (2020). SARS-CoV-2 Infects the Brain Choroid Plexus and Disrupts the BloodCSF Barrier in Human Brain Organoids. Cell Stem Cell 27, 951-961. doi:10. 1016/j.stem.2020.10.001

Pérez-López, F. R., Tajada, M., Savirón-Cornudella, R., Sánchez-Prieto, M., Chedraui, P., and Terán, E. (2020). Coronavirus Disease 2019 and Gender-
Related Mortality in European Countries: A Meta-Analysis. Maturitas 141, 59-62. doi:10.1016/j.maturitas.2020.06.017

Pine, A. B., Meizlish, M. L., Goshua, G., Chang, C. H., Zhang, H., Bishai, J., et al. (2020). Circulating Markers of Angiogenesis and Endotheliopathy in COVID19. Pulm. Circ. 10, 2045894020966547. doi:10.1177/2045894020966547

Planas, D., Veyer, D., Baidaliuk, A., Staropoli, I., Guivel-Benhassine, F., Rajah, M. M., et al. (2021). Reduced Sensitivity of SARS-CoV-2 Variant Delta to Antibody Neutralization. Nature 596, 276-280. doi:10.1038/s41586-021-03777-9

Poissy, J., Goutay, J., Caplan, M., Parmentier, E., Duburcq, T., Lassalle, F., et al. (2020). Pulmonary Embolism in Patients with COVID-19. Circulation 142, 184-186. doi:10.1161/circulationaha.120.047430

Potje, S. R., Costa, T. J., Fraga-Silva, T. F. C., Martins, R. B., Benatti, M. N., Almado, C. E. L., et al. (2021). Heparin Prevents In Vitro Glycocalyx Shedding Induced by Plasma from COVID-19 Patients. Life Sci. 276, 119376. doi:10.1016/j.lfs.2021.119376

Puelles, V. G., Lütgehetmann, M., Lindenmeyer, M. T., Sperhake, J. P., Wong, M. N., Allweiss, L., et al. (2020). Multiorgan and Renal Tropism of SARS-CoV-2. N. Engl. J. Med. 383, 590-592. doi:10.1056/nejmc2011400

Puntmann, V. O., Carerj, M. L., Wieters, I., Fahim, M., Arendt, C., Hoffmann, J., et al. (2020). Outcomes of Cardiovascular Magnetic Resonance Imaging in Patients Recently Recovered from Coronavirus Disease 2019 (COVID-19). JAMA Cardiol. 5, 1265-1273. doi:10.1001/jamacardio.2020.3557

Qadir, M. M. F., Bhondeley, M., Beatty, W., Gaupp, D. D., Doyle-Meyers, L. A., Fischer, T., et al. (2021). SARS-CoV-2 Infection of the Pancreas Promotes Thrombofibrosis and Is Associated with New-Onset Diabetes. JCI Insight 6. doi:10.1172/jci.insight.151551

Queisser, K. A., Mellema, R. A., Middleton, E. A., Portier, I., Manne, B. K., Denorme, F., et al. (2021). COVID-19 Generates Hyaluronan Fragments that Directly Induce Endothelial Barrier Dysfunction. JCI Insight 6. doi:10.1172/jci. insight.147472

Ramani, A., Pranty, A.-I., and Gopalakrishnan, J. (2021). Neurotropic Effects of SARS-CoV-2 Modeled by the Human Brain Organoids. Stem Cel Rep. 16, 373-384. doi:10.1016/j.stemcr.2021.02.007

Rapkiewicz, A. V., Mai, X., Carsons, S. E., Pittaluga, S., Kleiner, D. E., Berger, J. S., et al. (2020). Megakaryocytes and Platelet-Fibrin Thrombi Characterize MultiOrgan Thrombosis at Autopsy in COVID-19: A Case Series. EClinicalMedicine 24, 100434. doi:10.1016/j.eclinm.2020.100434

Ratchford, S. M., Stickford, J. L., Province, V. M., Stute, N., Augenreich, M. A., Koontz, L. K., et al. (2021). Vascular Alterations Among Young Adults with SARS-CoV-2. Am. J. Physiology-Heart Circulatory Physiol. 320, H404-H410. doi:10.1152/ajpheart.00897.2020

Rauch, A., Dupont, A., Goutay, J., Caplan, M., Staessens, S., Moussa, M., et al. (2020a). Endotheliopathy Is Induced by Plasma from Critically Ill Patients and Associated with Organ Failure in Severe COVID-19. Circulation 142, 1881-1884. doi:10.1161/circulationaha.120.050907

Rauch, S., Regli, I. B., Clara, A., Seraglio, P. M., Bock, M., Poschenrieder, F., et al. (2020b). Right Ventricular Myopericarditis in COVID-19: a Call for Regular Echocardiography. Minerva Anestesiol 86, 1253-1254. doi:10.23736/S03759393.20.14756-4

Ravindra, N. G., Alfajaro, M. M., Gasque, V., Huston, N. C., Wan, H., Szigeti-Buck, K., et al. (2021). Single-cell Longitudinal Analysis of SARS-CoV-2 Infection in Human Airway Epithelium Identifies Target Cells, Alterations in Gene Expression, and Cell State Changes. Plos Biol. 19, e3001143. doi:10.1371/journal.pbio.3001143

Rendeiro, A. F., Ravichandran, H., Bram, Y., Chandar, V., Kim, J., Meydan, C., et al. (2021). The Spatial Landscape of Lung Pathology during COVID-19 Progression. Nature 593, 564-569. doi:10.1038/s41586-021-03475-6

Rey, J. R., Caro-Codón, J., Rosillo, S. O., Iniesta, A. M., Castrejón-Castrejón, S., Marco-Clement, I., et al. (2020). Heart Failure in COVID-19 Patients: Prevalence, Incidence and Prognostic Implications. Eur. J. Heart Fail. 22 (12), 2205-2215. doi:10.1002/ejhf.1990

Richardson, S., Hirsch, J. S., Narasimhan, M., Crawford, J. M., Mcginn, T., Davidson, K. W., et al. (2020). Presenting Characteristics, Comorbidities, and Outcomes Among 5700 Patients Hospitalized with COVID-19 in the New York City Area. JAMA 323, 2052-2059. doi:10.1001/jama.2020.6775

Roberts, K. A., Colley, L., Agbaedeng, T. A., Ellison-Hughes, G. M., and Ross, M. D. (2020). Vascular Manifestations of COVID-19 - Thromboembolism and Microvascular Dysfunction. Front. Cardiovasc. Med. 7, 598400. doi:10.3389/ fcrm. 2020.598400 
Robinot, R., Hubert, M., De Melo, G. D., Lazarini, F., Bruel, T., Smith, N., et al. (2021). SARS-CoV-2 Infection Induces the Dedifferentiation of Multiciliated Cells and Impairs Mucociliary Clearance. Nat. Commun. 12, 4354. doi:10.1038/ s41467-021-24521-x

Rodríguez Rodríguez, M., Castro Quismondo, N., Zafra Torres, D., Gil Alos, D., Ayala, R., and Martinez-Lopez, J. (2021). Increased von Willebrand factor antigen and low ADAMTS13 activity are related to poor prognosis in covid-19 patients. Int. J. Lab. Hematol. 43, O152-O155. doi:10.1111/ijlh.13476

Rodríguez-Serrano, D. A., Roy-Vallejo, E., Zurita Cruz, N. D., Martín Ramírez, A., Rodríguez-García, S. C., Arevalillo-Fernández, N., et al. (2021). Detection of SARS-CoV-2 RNA in Serum Is Associated with Increased Mortality Risk in Hospitalized COVID-19 Patients. Sci. Rep. 11, 13134. doi:10.1038/s41598-02192497-1

Rogers, J. P., Watson, C. J., Badenoch, J., Cross, B., Butler, M., Song, J., et al. (2021). Neurology and Neuropsychiatry of COVID-19: a Systematic Review and MetaAnalysis of the Early Literature Reveals Frequent CNS Manifestations and Key Emerging Narratives. J. Neurol. Neurosurg. Psychiatry 92, 932-941. doi:10. 1136/jnnp-2021-326405

Romero-Duarte, Á., Rivera-Izquierdo, M., Guerrero-Fernández de Alba, I., PérezContreras, M., Fernández-Martínez, N. F., Ruiz-Montero, R., et al. (2021). Sequelae, Persistent Symptomatology and Outcomes after COVID-19 Hospitalization: the ANCOHVID Multicentre 6-month Follow-Up Study. BMC Med. 19, 129. doi:10.1186/s12916-021-02003-7

Romiti, S., Totaro, M., Laderchi, A., Peruzzi, M., Vinciguerra, M., and Greco, E. (2020). Case Report: Emergency CABG Following Failure of PTCA in a COVID-19 Patient. Front. Cardiovasc. Med. 7, 620610. doi:10.3389/fcvm. 2020.620610

Roncati, L., Ligabue, G., Fabbiani, L., Malagoli, C., Gallo, G., Lusenti, B., et al. (2020). Type 3 Hypersensitivity in COVID-19 Vasculitis. Clin. Immunol. 217, 108487. doi:10.1016/j.clim.2020.108487

Rubino, F., Amiel, S. A., Zimmet, P., Alberti, G., Bornstein, S., Eckel, R. H., et al. (2020). New-Onset Diabetes in Covid-19. N. Engl. J. Med. 383, 789-790. doi:10. 1056/nejmc2018688

Saeed, O., Castagna, F., Agalliu, I., Xue, X., Patel, S. R., Rochlani, Y., et al. (2020). Statin Use and In-Hospital Mortality in Patients with Diabetes Mellitus and COVID-19. J. Am. Heart Assoc. 9, e018475. doi:10.1161/JAHA.120.018475

Safizadeh, F., Nguyen, T. N. M., Brenner, H., and Schottker, B. (2021). Association of Renin-Angiotensin-Aldosterone System Inhibition with Covid-19 Hospitalization and All-Cause Mortality in the UK Biobank. Br. J. Clin. Pharmacol. 1, 1. doi:10.1111/bcp.15192

Sandoval, Y., Januzzi, J. L., Jr., and Jaffe, A. S. (2020). Cardiac Troponin for Assessment of Myocardial Injury in COVID-19. J. Am. Coll. Cardiol. 76, 1244-1258. doi:10.1016/j.jacc.2020.06.068

Sang, C. J., 3rd, Burkett, A., Heindl, B., Litovsky, S. H., Prabhu, S. D., Benson, P. V., et al. (2021). Cardiac Pathology in COVID-19: a Single center Autopsy Experience. Cardiovasc. Pathol. 54, 107370. doi:10.1016/j.carpath.2021. 107370

Santos, R. A. S., Sampaio, W. O., Alzamora, A. C., Motta-Santos, D., Alenina, N., Bader, M., et al. (2018). The ACE2/Angiotensin-(1-7)/MAS Axis of the ReninAngiotensin System: Focus on Angiotensin-(1-7). Physiol. Rev. 98, 505-553. doi:10.1152/physrev.00023.2016

Schaefer, I.-M., Padera, R. F., Solomon, I. H., Kanjilal, S., Hammer, M. M., Hornick, J. L., et al. (2020). In Situ detection of SARS-CoV-2 in Lungs and Airways of Patients with COVID-19. Mod. Pathol. 33, 2104-2114. doi:10.1038/s41379020-0595-z

Schimmel, L., Chew, K. Y., Stocks, C. J., Yordanov, T. E., Essebier, P., Kulasinghe, A., et al. (2021). Endothelial Cells Are Not Productively Infected by SARS-CoV2. Clin. Translational Immunol. 10, e1350. doi:10.1002/cti2.1350

Schwabenland, M., Salié, H., Tanevski, J., Killmer, S., Lago, M. S., Schlaak, A. E., et al. (2021). Deep Spatial Profiling of Human COVID-19 Brains Reveals Neuroinflammation with Distinct Microanatomical Microglia-T-Cell Interactions. Immunity 54, 1594-1610. e1511. doi:10.1016/j.immuni.2021. 06.002

Sharma, A., Garcia, G., Jr., Wang, Y., Plummer, J. T., Morizono, K., Arumugaswami, V., et al. (2020). Human iPSC-Derived Cardiomyocytes Are Susceptible to SARS-CoV-2 Infection. Cel Rep. Med. 1, 100052. doi:10. 1016/j.xcrm.2020.100052
Shetty, A. A., Tawhari, I., Safar-Boueri, L., Seif, N., Alahmadi, A., Gargiulo, R., et al. (2021). COVID-19-Associated Glomerular Disease. Jasn 32, 33-40. doi:10. 1681/asn.2020060804

Shi, S., Qin, M., Cai, Y., Liu, T., Shen, B., Yang, F., et al. (2020). Characteristics and Clinical Significance of Myocardial Injury in Patients with Severe Coronavirus Disease 2019. Eur. Heart J. 41, 2070-2079. doi:10.1093/eurheartj/ehaa408

Silverio, A., Di Maio, M., Citro, R., Esposito, L., Iuliano, G., Bellino, M., et al. (2021). Cardiovascular Risk Factors and Mortality in Hospitalized Patients with COVID-19: Systematic Review and Meta-Analysis of 45 Studies and 18,300 Patients. BMC Cardiovasc. Disord. 21, 23. doi:10.1186/s12872-020-01816-3

Singer, M. E., Taub, I. B., and Kaelber, D. C. (2021). Risk of Myocarditis from COVID-19 Infection in People under Age 20: A Population-Based Analysis. medRxiv 2021, 1. doi:10.1101/2021.07.23.21260998

Soehnlein, O., and Libby, P. (2021). Targeting Inflammation in Atherosclerosis from Experimental Insights to the Clinic. Nat. Rev. Drug Discov. 20, 589-610. doi:10.1038/s41573-021-00198-1

Sollini, M., Ciccarelli, M., Cecconi, M., Aghemo, A., Morelli, P., Gelardi, F., et al. (2021). Vasculitis Changes in COVID-19 Survivors with Persistent Symptoms: an [18F]FDG-PET/CT Study. Eur. J. Nucl. Med. Mol. Imaging 48, 1460-1466. doi:10.1007/s00259-020-05084-3

Song, E., Zhang, C., Israelow, B., Lu-Culligan, A., Prado, A. V., Skriabine, S., et al. (2021). Neuroinvasion of SARS-CoV-2 in Human and Mouse Brain. J. Exp. Med. 218, e20202135. doi:10.1084/jem.20202135

Sonzogni, A., Previtali, G., Seghezzi, M., Grazia Alessio, M., Gianatti, A., Licini, L., et al. (2020). Liver Histopathology in Severe COVID 19 Respiratory Failure Is Suggestive of Vascular Alterations. Liver Int. 40, 2110-2116. doi:10.1111/liv. 14601

Stark, K., and Massberg, S. (2021). Interplay between Inflammation and Thrombosis in Cardiovascular Pathology. Nat. Rev. Cardiol. 18, 666-682. doi:10.1038/s41569-021-00552-1

Stenmark, K. R., Frid, M. G., Gerasimovskaya, E., Zhang, H., Mccarthy, M. K., Thurman, J. M., et al. (2021). Mechanisms of SARS-CoV-2-Induced Lung Vascular Disease: Potential Role of Complement. Pulm. Circ. 11, 20458940211015799. doi:10.1177/20458940211015799

Strah, D. D., Kowalek, K. A., Weinberger, K., Mendelson, J., Hoyer, A. W., Klewer, S. E., et al. (2021). Worse Hospital Outcomes for Children and Adults with COVID-19 and Congenital Heart Disease. Pediatr. Cardiol. 1, 1. doi:10.1007/ s00246-021-02751-6

Sungnak, W., Huang, N., Bécavin, C., Berg, M., Queen, R., Litvinukova, M., et al. (2020). SARS-CoV-2 Entry Factors are Highly Expressed in Nasal Epithelial Cells Together with Innate Immune Genes. Nat Med. 26 (5), 681-687. doi:10. 1038/s41591-020-0868-6

Suzuki, Y. J., Nikolaienko, S. I., Dibrova, V. A., Dibrova, Y. V., Vasylyk, V. M., Novikov, M. Y., et al. (2021). SARS-CoV-2 Spike Protein-Mediated Cell Signaling in Lung Vascular Cells. Vasc. Pharmacol. 137, 106823. doi:10. 1016/j.vph.2020.106823

Sweeney, J. M., Barouqa, M., Krause, G. J., Gonzalez-Lugo, J. D., Rahman, S., and Gil, M. R. (2021). Low ADAMTS13 Activity Correlates with Increased Mortality in COVID-19 Patients. TH Open 05, e89-e103. doi:10.1055/s-0041-1723784

Szeghy, R. E., Province, V. M., Stute, N. L., Augenreich, M. A., Koontz, L. K., Stickford, J. L., et al. (2021). Carotid Stiffness, Intima-media Thickness and Aortic Augmentation index Among Adults with SARS-CoV-2. Exp. Physiol. 1, 1. doi:10.1113/EP089481

Tan, W. Y. T., Young, B. E., Lye, D. C., Chew, D. E. K., and Dalan, R. (2020). Statin Use Is Associated with Lower Disease Severity in COVID-19 Infection. Sci. Rep. 10, 17458. doi:10.1038/s41598-020-74492-0

Tang, N., Li, D., Wang, X., and Sun, Z. (2020). Abnormal Coagulation Parameters Are Associated with Poor Prognosis in Patients with Novel Coronavirus Pneumonia. J. Thromb. Haemost. 18, 844-847. doi:10.1111/jth.14768

Tenforde, M. W., Kim, S. S., Lindsell, C. J., Billig Rose, E., Shapiro, N. I., Files, D. C., et al. (2020). Symptom Duration and Risk Factors for Delayed Return to Usual Health Among Outpatients with COVID-19 in a Multistate Health Care Systems Network - United States, March-June 2020. MMWR Morb. Mortal. Wkly. Rep. 69, 993-998. doi:10.15585/mmwr.mm6930e1

Teuwen, L.-A., Geldhof, V., Pasut, A., and Carmeliet, P. (2020). COVID-19: the Vasculature Unleashed. Nat. Rev. Immunol. 20, 389-391. doi:10.1038/s41577020-0343-0 
Thacker, V. V., Sharma, K., Dhar, N., Mancini, G. F., Sordet-Dessimoz, J., and Mckinney, J. D. (2021). Rapid Endotheliitis and Vascular Damage Characterize SARS-CoV-2 Infection in a Human Lung-On-Chip Model. EMBO Rep. 22, e52744. doi:10.15252/embr.202152744

Thakur, K. T., Miller, E. H., Glendinning, M. D., Al-Dalahmah, O., Banu, M. A., Boehme, A. K., et al. (2021). COVID-19 Neuropathology at Columbia University Irving Medical Center/New York Presbyterian Hospital. Brain 144, 2696-2708. doi:10.1093/brain/awab148

Thwaites, R. S., Sanchez Sevilla Uruchurtu, A., Siggins, M. K., Liew, F., Russell, C. D., Moore, S. C., et al. (2021). Inflammatory Profiles across the Spectrum of Disease Reveal a Distinct Role for GM-CSF in Severe COVID-19. Sci. Immunol. 6, eabg9873. doi:10.1126/sciimmunol.abg9873

Townsend, L., Fogarty, H., Dyer, A., Martin-Loeches, I., Bannan, C., Nadarajan, P., et al. (2021). Prolonged Elevation of D-dimer Levels in Convalescent COVID19 Patients Is Independent of the Acute Phase Response. J. Thromb. Haemost. 19, 1064-1070. doi:10.1111/jth.15267

Unsworth, R., Wallace, S., Oliver, N. S., Yeung, S., Kshirsagar, A., Naidu, H., et al. (2020). New-Onset Type 1 Diabetes in Children during COVID-19: Multicenter Regional Findings in the U.K. Diabetes Care 43, el70-e171. doi:10.2337/dc20-1551

V'kovski, P., Gultom, M., Kelly, J. N., Steiner, S., Russeil, J., Mangeat, B., et al. (2021a). Disparate Temperature-dependent Virus-Host Dynamics for SARSCoV-2 and SARS-CoV in the Human Respiratory Epithelium. Plos Biol. 19, e3001158. doi:10.1371/journal.pbio.3001158

V'kovski, P., Kratzel, A., Steiner, S., Stalder, H., and Thiel, V. (2021b). Coronavirus Biology and Replication: Implications for SARS-CoV-2. Nat. Rev. Microbiol. 19, 155-170. doi:10.1038/s41579-020-00468-6

Van Dijk, C. G. M., Nieuweboer, F. E., Pei, J. Y., Xu, Y. J., Burgisser, P., Van Mulligen, E., et al. (2015). The Complex Mural Cell: Pericyte Function in Health and Disease. Int. J. Cardiol. 190, 75-89. doi:10.1016/j.ijcard.2015.03.258

Varga, Z., Flammer, A. J., Steiger, P., Haberecker, M., Andermatt, R., Zinkernagel, A. S., et al. (2020). Endothelial Cell Infection and Endotheliitis in COVID-19. The Lancet 395, 1417-1418. doi:10.1016/s0140-6736(20)30937-5

Venkatesan, P. (2021). NICE Guideline on Long COVID. Lancet Respir. Med. 9, 129. doi:10.1016/s2213-2600(21)00031-x

Villalba, N., Baby, S., and Yuan, S. Y. (2021). The Endothelial Glycocalyx as a Double-Edged Sword in Microvascular Homeostasis and Pathogenesis. Front. Cel Dev. Biol. 9, 711003. doi:10.3389/fcell.2021.711003

Von Meijenfeldt, F. A., Havervall, S., Adelmeijer, J., Lundström, A., Magnusson, M., Mackman, N., et al. (2021). Sustained Prothrombotic Changes in COVID19 Patients 4 Months after Hospital Discharge. Blood Adv. 5, 756-759. doi:10. 1182/bloodadvances.2020003968

Wagner, J. U. G., Bojkova, D., Shumliakivska, M., Luxán, G., Nicin, L., Aslan, G. S., et al. (2021). Increased Susceptibility of Human Endothelial Cells to Infections by SARSCoV-2 Variants. Basic Res. Cardiol. 116, 42. doi:10.1007/s00395-021-00882-8

Walls, A. C., Park, Y.-J., Tortorici, M. A., Wall, A., Mcguire, A. T., and Veesler, D. (2020). Structure, Function, and Antigenicity of the SARS-CoV-2 Spike Glycoprotein. Cell 181, 281-292. doi:10.1016/j.cell.2020.02.058

Wang, F., Wang, H., Fan, J., Zhang, Y., Wang, H., and Zhao, Q. (2020a). Pancreatic Injury Patterns in Patients with Coronavirus Disease 19 Pneumonia. Gastroenterology 159, 367-370. doi:10.1053/j.gastro.2020.03.055

Wang, L., Sievert, D., Clark, A. E., Lee, S., Federman, H., Gastfriend, B. D., et al. (2021a). A Human Three-Dimensional Neural-Perivascular 'assembloid' Promotes Astrocytic Development and Enables Modeling of SARS-CoV-2 Neuropathology. Nat. Med. 27, 1600-1606. doi:10.1038/s41591-021-01443-1

Wang, P., Nair, M. S., Liu, L., Iketani, S., Luo, Y., Guo, Y., et al. (2021b). Antibody Resistance of SARS-CoV-2 Variants B.1.351 and B.1.1.7. Nature 593, 130-135. doi:10.1038/s41586-021-03398-2

Wang, Y., Liu, S., Liu, H., Li, W., Lin, F., Jiang, L., et al. (2020b). SARS-CoV-2 Infection of the Liver Directly Contributes to Hepatic Impairment in Patients with COVID-19. J. Hepatol. 73, 807-816. doi:10.1016/j.jhep.2020.05.002

Wehbe, Z., Hammoud, S. H., Yassine, H. M., Fardoun, M., El-Yazbi, A. F., and Eid, A. H. (2021). Molecular and Biological Mechanisms Underlying Gender Differences in COVID-19 Severity and Mortality. Front. Immunol. 12, 659339. doi:10.3389/fimmu.2021.659339

Wei, J.-F., Huang, F.-Y., Xiong, T.-Y., Liu, Q., Chen, H., Wang, H., et al. (2020). Acute Myocardial Injury Is Common in Patients with COVID-19 and Impairs Their Prognosis. Heart 106, 1154-1159. doi:10.1136/heartjnl-2020-317007
Wenzel, J., Lampe, J., Müller-Fielitz, H., Schuster, R., Zille, M., Müller, K., et al. (2021). The SARS-CoV-2 Main Protease Mpro Causes Microvascular Brain Pathology by Cleaving NEMO in Brain Endothelial Cells. Nat. Neurosci. 24, 1522-1533. doi:10.1038/s41593-021-00926-1

West, A. P., Jr., Wertheim, J. O., Wang, J. C., Vasylyeva, T. I., Havens, J. L., Chowdhury, M. A., et al. (2021). Detection and Characterization of the SARSCoV-2 Lineage B.1.526 in New York. Nat. Commun. 12, 4886. doi:10.1038/ s41467-021-25168-4

Wong, C.-K., Luk, H. K.-H., Lai, W.-H., Lau, Y.-M., Zhang, R. R., Wong, A. C.-P., et al. (2020). Human-Induced Pluripotent Stem Cell-Derived Cardiomyocytes Platform to Study SARS-CoV-2 Related Myocardial Injury. Circ. J. 84, 2027-2031. doi:10.1253/circj.cj-20-0881

Wong, D. W. L., Klinkhammer, B. M., Djudjaj, S., Villwock, S., Timm, M. C., Buhl, E. M., et al. (2021). Multisystemic Cellular Tropism of SARS-CoV-2 in Autopsies of COVID-19 Patients. Cells 10, 1900. doi:10.3390/cells10081900

Woolf, S. H., Chapman, D. A., Sabo, R. T., Weinberger, D. M., Hill, L., and Taylor, D. D. H. (2020). Excess Deaths from COVID-19 and Other Causes, March-July 2020. JAMA 324, 1562-1564. doi:10.1001/jama.2020.19545

$\mathrm{Wu}, \mathrm{Z}$., and Mcgoogan, J. M. (2020). Characteristics of and Important Lessons from the Coronavirus Disease 2019 (COVID-19) Outbreak in China. JAMA 323, 1239-1242. doi:10.1001/jama.2020.2648

Xiao, F., Tang, M., Zheng, X., Liu, Y., Li, X., and Shan, H. (2020). Evidence for Gastrointestinal Infection of SARS-CoV-2. Gastroenterology 158, 1831-1833. e1833. doi:10.1053/j.gastro.2020.02.055

Yan, L., Ge, J., Zheng, L., Zhang, Y., Gao, Y., Wang, T., et al. (2021). Cryo-EM Structure of an Extended SARS-CoV-2 Replication and Transcription Complex Reveals an Intermediate State in Cap Synthesis. Cell 184, 184-193. e110. doi:10. 1016/j.cell.2020.11.016

Yan, R., Zhang, Y., Li, Y., Xia, L., Guo, Y., and Zhou, Q. (2020). Structural Basis for the Recognition of SARS-CoV-2 by Full-Length Human ACE2. Science 367, 1444-1448. doi:10.1126/science.abb2762

Yang, A. C., Kern, F., Losada, P. M., Agam, M. R., Maat, C. A., Schmartz, G. P., et al. (2021a). Dysregulation of Brain and Choroid Plexus Cell Types in Severe COVID-19. Nature 595, 565-571. doi:10.1038/s41586-021-03710-0

Yang, G., Tan, Z., Zhou, L., Yang, M., Peng, L., Liu, J., et al. (2020a). Effects of Angiotensin II Receptor Blockers and ACE (Angiotensin-Converting Enzyme) Inhibitors on Virus Infection, Inflammatory Status, and Clinical Outcomes in Patients with COVID-19 and Hypertension. Hypertension 76, 51-58. doi:10. 1161/hypertensionaha.120.15143

Yang, L., Nilsson-Payant, B. E., Han, Y., Jaffré, F., Zhu, J., Wang, P., et al. (2021b). Cardiomyocytes Recruit Monocytes upon SARS-CoV-2 Infection by Secreting CCL2. Stem Cel Rep. 16, 2274-2288. doi:10.1016/j.stemcr.2021.07.012

Yang, M., Chen, S., Huang, B., Zhong, J.-M., Su, H., Chen, Y.-J., et al. (2020b). Pathological Findings in the Testes of COVID-19 Patients: Clinical Implications. Eur. Urol. Focus 6, 1124-1129. doi:10.1016/j.euf.2020.05.009

Yao, H., Song, Y., Chen, Y., Wu, N., Xu, J., Sun, C., et al. (2020a). Molecular Architecture of the SARS-CoV-2 Virus. Cell 183, 730-738. doi:10.1016/j.cell. 2020.09 .018

Yao, X.-H., Luo, T., Shi, Y., He, Z.-C., Tang, R., Zhang, P.-P., et al. (2021). A Cohort Autopsy Study Defines COVID-19 Systemic Pathogenesis. Cell Res 31, 836-846. doi:10.1038/s41422-021-00523-8

Yao, Y., Cao, J., Wang, Q., Shi, Q., Liu, K., Luo, Z., et al. (2020b). D-dimer as a Biomarker for Disease Severity and Mortality in COVID-19 Patients: a Case Control Study. J. Intensive Care 8, 49. doi:10.1186/s40560-020-00466-z

Yeung, M. L., Teng, J. L. L., Jia, L., Zhang, C., Huang, C., Cai, J.-P., et al. (2021). Soluble ACE2-Mediated Cell Entry of SARS-CoV-2 via Interaction with Proteins Related to the Renin-Angiotensin System. Cell 184, 2212-2228. e2212. doi:10.1016/j.cell.2021.02.053

Yu, J., Yuan, X., Chen, H., Chaturvedi, S., Braunstein, E. M., and Brodsky, R. A. (2020). Direct Activation of the Alternative Complement Pathway by SARSCoV-2 Spike Proteins Is Blocked by Factor D Inhibition. Blood 136, 2080-2089. doi:10.1182/blood.2020008248

Zaid, Y., Puhm, F., Allaeys, I., Naya, A., Oudghiri, M., Khalki, L., et al. (2020). Platelets Can Associate with SARS-Cov-2 RNA and Are Hyperactivated in COVID-19. Circ. Res. 127, 1404-1418. doi:10.1161/circresaha.120.317703

Zareef, R. O., Younis, N. K., Bitar, F., Eid, A. H., and Arabi, M. (2020). COVID-19 in Pediatric Patients: A Focus on CHD Patients. Front. Cardiovasc. Med. 7, 612460. doi: $10.3389 /$ fcvm.2020.612460 
Zeng, W., Liu, G., Ma, H., Zhao, D., Yang, Y., Liu, M., et al. (2020). Biochemical Characterization of SARS-CoV-2 Nucleocapsid Protein. Biochem. Biophysical Res. Commun. 527, 618-623. doi:10.1016/j.bbrc. 2020.04.136

Zepp, J. A., and Morrisey, E. E. (2019). Cellular Crosstalk in the Development and Regeneration of the Respiratory System. Nat. Rev. Mol. Cel Biol 20, 551-566. doi:10.1038/s41580-019-0141-3

Zhou, F., Yu, T., Du, R., Fan, G., Liu, Y., Liu, Z., et al. (2020a). Clinical Course and Risk Factors for Mortality of Adult Inpatients with COVID-19 in Wuhan, China: a Retrospective Cohort Study. The Lancet 395, 1054-1062. doi:10.1016/ s0140-6736(20)30566-3

Zhou, P., Yang, X.-L., Wang, X.-G., Hu, B., Zhang, L., Zhang, W., et al. (2020b). A Pneumonia Outbreak Associated with a New Coronavirus of Probable Bat Origin. Nature 579, 270-273. doi:10.1038/s41586-0202012-7

Zhu, L., She, Z.-G., Cheng, X., Qin, J.-J., Zhang, X.-J., Cai, J., et al. (2020a). Association of Blood Glucose Control and Outcomes in Patients with COVID19 and Pre-existing Type 2 Diabetes. Cel Metab. 31, 1068-1077. e1063. doi:10. 1016/j.cmet.2020.04.021

Zhu, N., Zhang, D., Wang, W., Li, X., Yang, B., Song, J., et al. (2020b). A Novel Coronavirus from Patients with Pneumonia in China, 2019. N. Engl. J. Med. 382, 727-733. doi:10.1056/nejmoa2001017
Ziegler, C. G. K., Allon, S. J., Nyquist, S. K., Mbano, I. M., Miao, V. N., Tzouanas, C. N., et al. (2020). SARS-CoV-2 Receptor ACE2 Is an Interferon-Stimulated Gene in Human Airway Epithelial Cells and Is Detected in Specific Cell Subsets across Tissues. Cell 181, 1016-1035. doi:10.1016/j.cell.2020.04.035

Conflict of Interest: The authors declare that the research was conducted in the absence of any commercial or financial relationships that could be construed as a potential conflict of interest.

Publisher's Note: All claims expressed in this article are solely those of the authors and do not necessarily represent those of their affiliated organizations, or those of the publisher, the editors, and the reviewers. Any product that may be evaluated in this article, or claim that may be made by its manufacturer, is not guaranteed or endorsed by the publisher.

Copyright (C) 2022 Martínez-Salazar, Holwerda, Stüdle, Piragyte, Mercader, Engelhardt, Rieben and Döring. This is an open-access article distributed under the terms of the Creative Commons Attribution License (CC BY). The use, distribution or reproduction in other forums is permitted, provided the original author(s) and the copyright owner(s) are credited and that the original publication in this journal is cited, in accordance with accepted academic practice. No use, distribution or reproduction is permitted which does not comply with these terms. 